\title{
Doris Schönefeld*
}

\section{A constructional analysis of English un-participle constructions}

DOI $10.1515 / \operatorname{cog}-2014-0017$

\begin{abstract}
The present paper reports on an investigation into an English un-participle pattern that is called unpassive, or is described as an adjectival passive. The main characteristic of the pattern is an (adjectival) past participle prefixed by un-, which is used as a predicative complement to a verb. Besides the different terms used for the pattern, there is also some indeterminacy with respect to its particular form. All of the descriptions focus on the verb BE, but mention is also made of Go and REMAIN. That is, the specifications of the pattern's formal side differ to some extent. To provide information on this issue and to get hold of potential (verb-related) differences in the pattern's function, we conducted an empirical analysis from a usage-based construction grammar perspective. Our focus is on the form-function interplay of the pattern in order to gain information about its constructional status and its exact formal and semantic make-up. The database selected for this study is the BNC, from which all occurrences of 'verb plus un-participle' were extracted. The data were submitted to collexeme and covarying collexeme analyses to identify the spectrum of meanings/functions associated with these forms, and distinctive collexeme analyses were carried out to see whether the un-participles found pattern differently with the individual verbs. The results indicate that, on closer examination, the un-participle construction does not represent a homogeneous category, but must be seen as a schematic template of related, though different, usage events that may have expanded analogously from a prototype construction. On the basis of our analyses and informed by findings from developmental studies, we suggest that the related constructions form a network.
\end{abstract}

Keywords: un-participle construction, unpassive, (adjectival) passive, collostruction analysis

*Corresponding author: Doris Schönefeld, Institute for British Studies, Leipzig University, Beethovenstr. 15, Leipzig, Saxony D-04107, Germany, E-mail: schoenefeld@uni-leipzig.de 


\section{Introduction}

Participles have always been considered as exhibiting features of two word classes, namely those of verbs and adjectives. In other words, they 'participate' in two word classes, hence the name ${ }^{1}$ (cf. Robins 1992: 331; OED'2: etymology of the word 'participle', for example). Therefore, it does not come as a surprise that constructions containing participles may have a similar ambivalent nature. This holds for both types of participles usually distinguished in English, present and past participles, and for the constructions they enter into, as examples (1)-(5) show:

(1) While Geoffrey was intriguing against him in Paris, Richard was occupied with an invasion of Toulouse. (EFV) ${ }^{3}$

(2) The face, too, was intriguing, its strong lines accentuated by severely cropped hair ... (HNJ)

(3) ..., a distance that was covered in fourteen hours by passenger trains. (A64)

(4) When the camera crew arrived three days later, the shelter was covered in graffiti and all its glass had been shattered. (A2G)

(5) When the land was covered by ice sheets, about 20,000 years ago, the highest peaks, ... (B1H)

In (1) we have a progressive construction, giving an eventive or verbal reading. (2) is a copular construction, ascribing a state to the subject referent. (3), a passive construction, induces an event reading, and (4), a stative passive, is a construction that also ascribes a state to the subject referent. (5) is a passive construction which is ambiguous between an eventive and a stative reading.

We can basically see that the participles induce either a dynamic or a stative reading, i.e., the complete utterances express that the subject referent is either involved in some kind of activity (event), or it is the carrier of a state. As

1 According to Robins (1992: 326), Dionysius Thrax summarized the classical list of parts of speech to contain 'metoché', which he defined as "a part of speech sharing the features of rhêma and ónoma”. In Latin grammars (such as Priscian's Institutiones grammaticae) the Greek word is translated into the Latin term 'participium'.

2 We used the electronic version of the OED, last accessed on 5 October 2013.

3 If not indicated otherwise, all examples are taken from the British National Corpus (BNC). 
example (5) shows, some of the uses allow for both readings, and only a wider context may help to disambiguate the utterance, if need be.

In the English language, a special type of past participles has been identified, which is said to express stative readings only and hence triggers unambiguous meanings, the so-called un-participle as illustrated in (6) and (7): ${ }^{4}$

(6) He pretended to be unsurprised. (AON)

(7) The material is unabridged and wholly authentic. (BNC, CLL, 842)

Such structures have been described as adjectival passives or 'unpassives', for example. However, we hypothesize that their allusion to passive constructions is deceptive, as their functional specification is that of a copular clause pattern, for which the active-passive alternation is not an issue. This hypothesis prompted an empirical investigation of the 'unpassive' from a usage-based construction grammar perspective. We generally follow the model of construction grammar developed by Goldberg $(1995,2003,2006)$ and draw on the assumption that (frequency of) usage is indicative of a native speaker's linguistic knowledge, of his constructional repertoire, as is argued in Bybee and Hopper (2001), Bybee (2006), and Diessel (2007), for example. This knowledge is thought to emerge from the experience of constructional exemplars, an idea that has been explored in Bybee (2006, 2013), and Ellis and Larsen-Freeman (2009). In particular, the investigation aims at the close analysis of the pattern(s) at work in the respective usage events and the specification of their functional load. The study at hand draws on (British) English usage data extracted from the British National Corpus (BNC). These were submitted to different types of collostruction analysis, whose results are then discussed with regard to their implications for the construction(s) the pattern at issue relates to.

The remainder of the paper is structured as follows. Section 2 provides a detailed description of the pattern under analysis. Section 3 describes the data this study is based on and elaborates on the methods used for their processing and interpretation. Section 4 contains the results and is followed by their discussion in Section 5. Section 6 concludes with the suggestion of a network of English constructions featuring an un-participle as part of their predicates.

4 We are aware of the existence of such forms in other languages, such as German, but the focus of this study is on participles in English. 


\section{The pattern under analysis}

The pattern investigated here is typically instantiated by such utterances as given in (6) and (7) above. For now, we assume that the pattern is ' $\mathrm{X}$ BE unparticiple', although descriptions in the literature are ambivalent with respect to the form the construction actually has. Huddleston and Pullum (2002: 1,440) suggest variation in the verb slot, giving example sentences with the verbs BE, GO and REMAIN, and Hust (1977: 38) notes that the un-participles can also occur as complements of noninchoative Go. But since BE is always treated as the typical verb in this construction, we will, for the moment, take $\mathrm{BE}$ as the verb specific to the pattern. We claim that the pattern represents a construction in the sense of a form-function pairing (cf. Goldberg 2006: 5).

Regarding the construction's formal specification, the verb (вE) is complemented by an un-participle, which, in this construction, is considered to be adjectival. This categorical alignment is supported by a number of criteria or diagnostics:

(i) there is no verbal base of the participle (such as *unabridge for [7]); ${ }^{5}$

(ii) the participial forms can be potentially modified by gradators (such as deeply unsatisfied);

(iii) they can be coordinated with genuine adjectives (as in [7]).

The formal make-up classifies the pattern as a partially lexically filled construction, i.e., a mid-level construction as far as schematicity is concerned. The pattern's semantic or functional characterisation, gleaned from examples (6) and (7), is the ascription of a property or state to the referent of the subject. The latter (he and material respectively) are characterised as being unsurprised and unabridged. This meaning is consistent with that of a copular argument construction which I call attributive construction (cf. Schönefeld 2012). ${ }^{6}$ Upon closer inspection, this is, however, not specific enough, because the state

5 From (i) it becomes obvious that the past participle must result from construing the final state of an event (abridged < abridge), which in turn is negated by adding the prefix -un (=unparticiple).

6 I use the term 'attributive construction' in analogy with Hampe and Schönefeld (2006: 135). There, we call a "complex-transitive construction with adjectival object complements "attributive", ... [vs] "resultative", to mark out the semantic difference." Compare find X difficult vs make $X$ difficult, where the former 'attributes' a property to $\mathrm{X}$ and the latter describes its resultant state. In a copular construction, the property is ascribed to the subject: $X$ is difficult. Hence, (subject-related) attributive construction (vs subject-related resultatives, as in $X$ becomes difficult). 
ascribed to the subject in this pattern can be further qualified as due to an 'absent event', an event that did not take place, that is. ${ }^{7}$

Constructions matching this pattern have been recognized in both linguistic theorizing and representative descriptions of the grammar of English, but analyses and names are far from being uniform. Some authors discuss them directly as 'unpassives' (e.g., Hust 1977; Bresnan 1978; Chomsky 1981: 54-55), others list them in the discussion of 'adjectival passives' (e.g., Chomsky 1981; Huddleston and Pullum 2002; Maienborn 2007: 83), for which alternative terms can be found: 'Zustandspassiv' (stative passives') (e.g., Maienborn 2007: 83), or statal passives (e.g., in Comrie 1981: 72). That means, 'unpassives' are generally associated with adjectival/stative passives, which, in English, are identical in form with verbal/eventive/dynamic passives. ${ }^{8}$ A closer look, however, reveals a more complex picture than this. Chomsky $(1981: 54-55,119)$ notes that participles and unpassives do not have the same properties. According to the feature classification used in generative theory, a participle has the feature $[+\mathrm{V}]$, whereas unpassives have $[+\mathrm{V} ;+\mathrm{N}]$ (which is the feature description for adjectives). Quirk et al. (1985: 167-168) list 'unpassives' in their description of 'semipassives', which lack a "clear correspondence with an active verb phrase or active clause, and ... whose members have both verbal and adjectival properties". 9 Huddleston and Pullum (2002: 1,440) discuss 'unpassives' separately under adjectival passives, qualifying them as "unambiguously adjectival", since the negated participial forms do not relate to a verbal base (*unsurprise, *untouch). The ambiguity postulated for adjectival passives "between a verbal passive and a complex-intransitive clause containing an adjectival passive as predicative complement" (Huddleston and Pullum 2002: 1,436) is thus annulled for the unpassive. All these descriptions represent the unpassive participles as somewhat special and different from the other, 'genuine' participles, ${ }^{10}$ which

7 The description at hand is informed by what was found about the semantics of the unparticiple construction with the verb Go by Bourdin (2003) and Schönefeld (2012).

8 This is different in German, for example, where adjectival (=stative) passives are formed by a form of the verb SEIN and the past participle of the verb denoting the event talked about vs verbal (=dynamic) passives, which employ a form of the verb WERDEN and the past participle: Der Tisch ist gedeckt vs. Der Tisch wird gedeckt.

9 At a later place they qualify 'participial adjectives' that have no corresponding verbs (such as * unexpect) as obviously not representing participles (cf. Quirk et al. 1985: 413), that is, they must be adjectives.

10 Distinctions are made between adjectival uses and passive participles (cf. Israel et al. 2000), adjectival and verbal participles (McIntyre 2013), verbal and adjectival passives (cf. Wasow 1977; Embick 2004; Emonds 2006; Toyota 2008, who, just as Embick did, adds a third class: resultative passives; Meltzer-Asscher 2010). 
raises the question of just what kind of structures these participles, and the more complex expressions in which they are used, actually are. Though the pattern's form (BE plus past participle) and the adjectival status of the un-participle is a perfect prompt for its allocation to English (adjectival) passives, it must be asked if also its functional specification is compatible with them. That is, we have to see what the semantic-functional load of passives is as compared to that of unpassives. Passives (just like actives) are concerned with the expression of canonical events "in which an agent acts on a patient to induce a change of state”. (Langacker 2008: 357). The passive portrays such an event from the perspective of the PATIENT, as in (8):

The dishes have been washed (by X).

That is why it is also verbal (or dynamic) by default, an entity (the dishes) is depicted as being affected by an event, an action, that is. If construed as a stative passive, the same entity is characterised as being in a state resulting from the action named by the verb. This state can often be paraphrased by a suitable adjective, such as The dishes are clean for example (8). The stative construal follows from the meaning of the past participle, which "highlight[s] the end of the verbal process, focusing either the final participant or the final state" (Langacker 2008: 121-122), in conjunction with the suppression of an otherwise processual meaning of ' $\mathrm{BE}+$ participle' in the dynamic passive construction. Hence, both types of passive are related to a transitive scenario. The function of the passive consists in assigning the status of topic to the PATIENT (the entity acted on), producing an alternative to the prototypical construal of a transitive event with the AGENT (the entity initiating and carrying out the action) as topic. In the dynamic passive, the PATIENT is construed as the undergoer of an action, in the stative passive - as being in a state that follows from an action directed at it.

In the case of the unpassive, the construal is subtly different: The topic is neither AGENT nor PATIENT, but it is an entity in a state which the un-participle qualifies as 'not being exposed or subjected to V'. That is, the state is due to the absence or non-occurrence of an action (as in (7): material is unabridged) rather than resulting from an event affecting a PATIENT. Therefore, the topic phrase carries the semantic role of CARRIER (of state or attribute) or THEME (defined as 'what is in a state or in a change of state'). ${ }^{11}$

11 It should be noticed that there is no general agreement on the number and nature of semantic roles, so that there exist several lists (cf. Saeed 2008 [1997]: 148). Therefore, the labels used here are briefly described. 
The functional specifications of the pattern suggest that we are concerned with two different types of constructions. On the one hand, we are talking about argument-structure constructions for the expression of basic scenes (cf. Goldberg 1995: 3-5, 1998, for example), namely transitive clauses, reflecting Langacker's canonical event model (cf. Langacker 2008: 382-383), and attributive constructions, ascribing a property/state to an entity. On the other hand, we are discussing constructions that have a discursive function, bringing about differences in information structuring (as in cleft sentences and the active-passive alternative). Given these two types of construction, the issue is how they figure in the pattern under analysis: Is it a passive transitive ASC, rendering a person's or thing's state as resulting from a transitive event, or is it an attributive ASC, essentially just specifying a person's or thing's state, with both a PATIENT and the idea of change virtually absent. Usage data require that resultative ASCs, expressing a change-of-state, be included in the analysis.

To disentangle the constructions potentially interacting or 'amalgamating' in the un-participle pattern, we conducted an analysis of authentic usage, searching for the clarification of a number of questions:

(i) What are the characteristics of such uses?

(ii) How do they relate to other English passive constructions of the form $\mathrm{BE}+$ past participle

a. Do they represent the same pattern? More particularly, are they (adjectival) passives?

b. Do they represent different patterns? If so, what are these patterns and what are the relations between them?

(iii) How lexically specific are such constructions?

The descriptions available in grammars of English suggest that the pattern is more schematic than ' $\mathrm{X}$ BE un-participle' in that the verb slot is not invariably filled by BE, so that the type of the pattern's verbal slot is in need of clarification. Is the slot lexically specific (i.e., filled by an individual verb), is it verb groupspecific or can it be filled by a word of the class $\mathrm{V}$ in general?

These questions will be taken up in the discussion in Section 5. However, we need to decide now which label to use for the pattern. 'Unpassive' is a biased term in that it suggests the pattern's inclusion in the category of passives. That is why we opt for a more neutral term to label it, namely un-participle construction (UPC).

In the following section, information is given regarding the data used for the investigation and the methods employed in the analysis. 


\section{Material and methods}

The analysis of the un-participle construction is based on authentic English usage data taken from the BNC. The data were extracted from this corpus using $\mathrm{R}$ for searches of pattern tokens with particular verbs (BE, GO, REMAIN, COME RuN, for example). ${ }^{12}$ For searches with a schematic V slot, options provided by the BYU-corpora (http://corpus.byu.edu/bnc/) were used. ${ }^{13}$ In total, the queries returned all sequences of verb and un-prefixed word tagged as adjective (which is the tag attached to un-participles in the BNC), either following the verb directly, after an intervening adverb or after an adjective and the conjunct and. The un-participles had to be manually separated from other un-prefixations and were made the database of this investigation. They were examined for what they say about the formal side of the un-participle pattern and about the meaning(s)/ function(s) associated with the form. The findings were then used for the exploration of the more general questions raised above.

The methods employed for processing and (statistically) interpreting the data are taken from the family of collostruction analysis developed by Gries and Stefanowitsch (cf. Stefanowitsch and Gries 2003, 2009; Gries and Stefanowitsch 2004, for example). In particular, we used the methods of (simple) collexeme analysis, covarying collexeme analysis and multiple distinctive collexeme analysis. All calculations were done in $\mathrm{R}$, using an interactive programme, Coll.analysis 3.2, an R script written by, and freely available from, Stefan Th. Gries (2007).

The first method identifies the words attracted to one of a construction's functionally defined slots (cf. Stefanowitsch and Gries 2003; Gries and Stefanowitsch 2004), that is, it specifies the collocational preferences of a particular constructional slot, and, thus, helps to elaborate the meaning of the respective construction. ${ }^{14}$ In our study, collexeme analyses contribute to the semantic characterisation of the un-participle pattern by revealing which participial collexemes are particularly attracted to it.

12 The R-scripts used draw on a script written by Stefan Gries.

13 To illustrate these queries, $<\operatorname{word}(\mathrm{s})$ : $\mathrm{un}^{\star}$. $\left[\mathrm{j}^{\star}\right]$; collocate $\left[\mathrm{v}^{\star}\right]$ to the left (position 1)> returned all sequences of verb and adjacent $u n$-prefixed adjectives.

14 Technically speaking, it takes into account the (raw) frequency of a particular word in a particular construction, and the (raw) overall frequencies of the word and the construction in the corpus. From these frequencies, a measure of attraction/repulsion between a word and a construction is calculated, called collostruction strength. For its calculation, the Fisher-Yates Exact test is used, because it does not require the tested data to be normally distributed and can be used for data with very small numbers of observation (cf. Stefanowitsch and Gries 2003: 217-218). The value is given in the form of the negative logarithm to the base of ten of the p-values. 
The method of covarying collexeme analysis investigates the interactions between words occurring in two different slots of the same construction. It thus helps to determine the potential semantic relationships existing between these two slots (cf. Stefanowitsch and Gries 2005: 11). The type of analysis carried out here is item-based, i.e., covariation is analysed in a subcorpus consisting of the total of instances of the respective pattern, the overall corpus frequencies are thus neglected (cf. Stefanowitsch and Gries 2005: 23). ${ }^{15}$

The third method employed, multiple distinctive collexeme analysis, points to the differences between functionally similar constructions. It is used to reveal which collexemes are distinctive for a particular construction as compared with the respective collexemes in other (similar) constructions. Identifying the constructions' distinctive attracted (and repelled) collexemes, the analysis helps to elaborate the semantic specifics of one construction against those of the others. ${ }^{16}$

\section{Results}

Surprisingly, the corpus hits do not just contain the verbs BE, REMAIN and Go preceding the un-participle, but there is a considerable number of other verbs to be found. We can identify 268 types, representing 11,291 tokens. On closer inspection, however, it turned out that there are quite a few false hits among them. These are mainly instances representing a scenario where the un-participle is related to the object of the event, as in (9).

(9) vegetable oils ..., they can be used undiluted in the bath ... (B06)

Despite the adjacency between verb and un-participle, these cases do not represent UPCs as defined for this study. Rather, they are passives of complextransitive ASCs, with the PATIENT subject referents (here: vegetable oils) additionally characterised by a depictive un-participle. Moreover, there are instances of (mono)transitive scenarios with the object postponed, as in (10)

15 The significance of the relevant co-occurrence frequencies, called the covarying collexeme strength, is again calculated by means of the Fisher-Yates exact test, drawing on frequency data for the two words in the two constructional slots to be investigated and all other words encountered in the same slots of the construction.

16 Since these methods are by now well-known in (quantitative) corpus linguistics, we abstain from describing them in more detail and refer the reader to the literature cited above, if further information is required. 

... and keep undisturbed the love that was between us. (ABL)

Altogether we identified 87 verb types that occurred in such patterns only (e.g., elect, make, release, etc.), and 6 types (e.g., leave, return, manage) that occurred in such patterns to some extent (548 tokens in total). These instances do not qualify for this analysis, as they represent ASCs different from the ones under analysis.

In the following, we will inspect the remaining hits (181 verb types, 10,743 tokens) from the perspective of the finite verbs and of the un-participles.

\subsection{Finite verbs in UPCs}

The 181 verb types exhibit huge differences in their token numbers, as illustrated in Table 1.

Table 1: Token frequencies of selected verbs in the UPC (a list of the top 30 verbs is given in Appendix A).

\begin{tabular}{lrrrrr}
\hline verb (rank) & be (1) & remain (2) & go (3) & come (8) & sit (28) \\
\hline Tokens & $<7,000$ & 1,500 & $<600$ & $>100$ & 14 \\
\hline
\end{tabular}

The respectable token numbers found for some of the verbs in the UPC suggests that, at lower levels of abstraction, the un-participle construction subsumes some verb-specific constructions, such as be + un-participle, remain + etc., and a number of verb-group-specific constructions, such as change-of-state $\mathrm{V}$ + un-participle, motion $\mathrm{V}+$ etc. on a higher level of schematicity.

Our further investigation focuses on the characteristics of these more specific constructions. In accordance with the usage-based assumption that more schematic constructions emerge from experiencing and recognizing identical and similar individual usage events (cf. Hopper 1987; Langacker 1987, 2000; Goldberg 1995, 2003, 2006; Barlow and Kemmer 2000; Bybee and Hopper 2001; Bybee 2006; Diessel 2007, for example), we start out from the verb-specific constructions, extending the discussion to verb-group specific constructions and a potential even more abstract un-participle construction if this is warranted by the data.

To begin with, it is notoriously difficult to say which of the candidate constructions actually represent verb-specific constructions, since it is unclear how many instances of a verb-specific form a language user needs to experience in order to store it as a separate construction. Although this problem has been discussed for long and empirical tests have been carried out for what happens 
with (very) high and low frequent forms, Bybee (2006: 715), for example, points out that currently it is impossible to specify "what these values mean in numerical terms." Therefore, in this investigation, we only look at the higher end of the token numbers, assuming that the less frequent forms may be formed by analogy with more typical verbs of the same group. That means that we take the more frequent verbs in the un-participle pattern as candidates for verbspecific constructions and inquire into their characteristics by looking at both the verb semantics and the semantic aspects contributed by the un-participles they co-occur with.

The contributions of the verbs to the description of the constructional meanings can be detected quite straightforwardly. The verb BE signals a copular scenario where a state is ascribed to the subject referent. The state is construed as it presents itself at the reference time. Further aspectual and modal notions may be added by the respective markers. Some of the other verbs add such notions to the characterization of the state as part of their semantics. The verb REMAIN expresses persistence of an anterior (i.e., "pre-existing") state. ${ }^{17}$ Therefore, the REMAIN UPC depicts a previously given state (of the subject referent) as continuing without change. conTINUE, which superficially seems synonymous to REMAIN, expresses persistence of a current state in the time after a reference point, posterior to it. So, it is associated with a prospective orientation, and in a way is the converse of REMAIN. SEEM and APPEAR mark the state ascription as subjective, adding a notion of epistemic modality, namely, uncertainty. APPEAR may furthermore add the notion of 'outward show' (cf. OED sense 11). The subject referent's state is given as what it appears to be, as opposed to fact, which would need the verb $\mathrm{BE}$ instead. The verb BEcome, a typical English 'resulting copula' (for the term, see Quirk et al. 1985: 1,172), contributes its copular meaning of change-ofstate, fusing with (subject-related) resultative ASCs.

Go in the UPC has two meanings. Firstly, if used in an attributive ASC, it portrays a state as moving through time, as 'ongoing', as in ... his predicament went unnoticed (K5D). The verb's original motion sense, bleached though it has, contributes the notion of persistence, which makes the meaning similar to that of continuE. The state is construed as relevant at the reference time. Secondly, go may unify with the un-participle as a depictive construction, ${ }^{18}$ with the verb

17 This shade of meaning is made prominent in descriptions of the verb's meaning (cf OED, sense 5a (of seem): continue to be, OED 6a: to continue to exist, have permanence, be still existing or extant).

18 The term depictive goes back to Halliday (1967). It represents one type of secondary predication, the other type being resultatives (cf. Rapoport 1990, 1999; Aarts 1995; Rothstein 2003, 2006, for example). The depictive subtype contains a "predicative attribute" which 
retaining its motional sense as in He went unnoticed through Swiss emigration (FSF). Such uses are etymologically prior and attributive senses have been identified as a context-induced reinterpretation of originally depictive constructions, with the verb Go undergoing a desemanticization into a quasi-copular verb (cf. OED sense 23 of Go). The semantic potential of comE in a UPC is even greater. Firstly, it occurs in (subject-related) resultative ASCs, expressing a change of state (X come untucked). Secondly (though rarely), in attributive ASCs COME predicates a state (The AM9 kit comes unfinished [CG5]). Thirdly, it is encountered in intransitive motion ASCs with depictive participles, which inform about the mover's state (X come unprepared). Run combines with depictive uses of the un-participle, too. Most of the instantiations express a state concomitant with the motion (X run unchecked). The verb's motional meaning may be attenuated, with the whole construction construing a (dynamic) situation as unchanging, quasi 'stative', rather than focussing on a moving trajector: $\mathrm{X}$ run unchanged. This suggests that - in analogy with instances of Go and COME UPCs - also RUN UPCs are receptive to grammaticalization, bleaching to an attributive meaning. As the depictive uses represent secondary predications, they are peripheral to our investigation of the (non-secondary) predications of passives and UPCs. Apart from the uses just discussed, a substantial group of other (mainly low-frequent) verbs were found to combine with depictive un-participles (cf. example [11]), such as approach (1 token), expand (1), speak (1), act (3), persist (5), drive (4), etc.

\section{(11) Bnezet approached unnoticed}

Such verbs were disregarded in the further analysis if they occurred exclusively in depictive uses.

\subsection{Collexemes in the UPCs}

Inspecting the collexemes, we note that the UPCs attract un-participles of two types, adjectival un-participles (which have no corresponding verb, such as *undigest, *unexplain, etc.) and those relating to un-prefixed verbs (such as undelete, undisguise, unplug, etc.), known as reversative verbs. Etymological

describes a characteristic of one of the participants associated with the main predicate. This characteristic is rendered as concomitant to the event encoded by the main predicate, which sets it apart from a resultative, where it is rendered as the result of the event (cf. Halliday 1967; Himmelmann and Schultze-Berndt 2005; Rothstein 2006: 210). 
considerations reveal that this is because the prefix un- goes back to two different origins. The one form is the negative prefix un- which is also found in German and relates to Latin in-, the other form is the reversative prefix on $(d)$ which is related to German ent- and Greek anti- (cf. Zimmer 2009). According to Zimmer's research, “[t]hese two prefixes merged into one form, un-, and they've been semantically intertwined ever since.” (Zimmer 2009). That is, what looks the same from a synchronic perspective turns out to be two homonymous constructions. In the former case we are concerned with a participle that was negated by the negative prefix un-, so that the whole form describes a state that is the result of the absence of an event, as in unmodified vs modified. In the latter case, the prefix (now also un-) modifies a verb to express the reversal of the process named by the prefixless verb, as in cover and uncover. In combination with a form of $\mathrm{BE}$, the latter participles seem to form ordinary passives, construing the event from the perspective of its undergoer or PATIENT with both dynamic and stative readings available. However, usage data indicate that it is not as simple as that. Examples like (12) are canonical (dynamic) passive constructions. The focus is on the process affecting the PATIENT rather than its final state, though the latter interpretation is possible in the respective contexts, as suggested for (13), representing a stative passive:

(12) ... and more drugs were uncovered in follow-up searches ... (HJ4)

(13) There was no sign to say the drain was uncovered and I fell down it ... (K97)

Here, the drain had been uncovered at some time before and was now open to fall into it. However, 'reversative' participles may also be given an adjectival un-participle reading: 'the drain was not covered'. That is, UPCs with alleged reversative participles need not necessarily relate to reversative verbs. They may have two readings depending on the wider context, if - due to the historical merger mentioned above - they are homonymous with adjectival un-participles: $\mathrm{BE}$ uncovered may mean to reverse the action of covering or merely to not have been exposed or subjected to the action of covering. Such homonymous forms cannot always be scrupulously distinguished. Examples (14) and (15) make it obvious that for a distinction sometimes even the wider context is not helpful, so that both readings are available ('without arms' or 'with the arms taken away' in (14) and 'not diminished' or 're-established after having been diminished' in [15]):

(14) ... Colombian-born Lieutenant Roberto Paz, was unarmed when he and other marines in civilian clothes were stopped at a roadblock. (AAB) 
... whose brilliance was undiminished by having to appeal to an audience whose IQ was not less than 200. (AMC)

For many of the ambiguous un-participles identified, habitual use may give rise to preferred interpretations, so that, e.g., $X$ was uncovered may be more strongly associated with the reversative verb meaning, whereas, e.g., $X$ was unconvinced will most likely trigger the stative reading of 'not convinced'. However, there are uses which do not comply with these expectations, as shown in (16) and (17)

... the part of George's face that was uncovered was almost numb with cold ... (C98)

(17) Others have been unconvinced by the search for an overall ... logic (B2L)

Because of these ambiguities, ${ }^{19}$ un-participles per se resist neat categorization in these terms without reviewing the data case by case. We, therefore, do not make an a priori distinction between reversative participles and adjectival un-participles before submitting the data to our analyses at the cost of including passives in the overall analyses and calculations. At a later stage, the distinction will be made when required. If, then, the forms are found to be reversative participles (as in [12]), the complete constructions will align with passives and mean the undoing of a process (or the PATIENT's state arrived at thereafter). However, if the un-participles are adjectival (as in [16]), they will ascribe states to the subject referents that follow from not being subjected to V. It seems that states expressed by this pattern are rendered as deviating from a default situation: they are unusual, unexpected, or even unpreferred, or unwanted, as in be/ become unemployed, become unstabilized, unbalanced, be unknown, remain unsolved, unconvinced, seem unconcerned, go unnoticed, for example. This can be attributed to the prefix un-, changing the 'unmarked' property named by the 'prefixless' participle into its opposite, and, since un-participles are constitutive of the pattern, the notion of 'non-default' may be assumed to be central to its meaning. Support along these lines can be offered by quite a few strongly associated collexeme pairs (of subject fillers and un-participles) identified in the respective analyses of some verb-specific patterns (cf. Appendix C). These pairs (e.g., cases going unreported or letters going unanswered) allude to verbobject collocations (report cases or answer letters), whose existence can be assumed to "reflect the recurrence of similar situations in human affairs"

19 Even for seemingly clear adjectival cases, such as unasked, unattached, or unbiased, the OED lists related reversative verbs, so that both meanings are available in principle. 
(Sinclair 1991: 110). That is, the collocations correlating with the 'normal course of events' represent default situations, so that the 'absence' of such events can indeed be seen as running counter to one's expectations. It has been found that the notion of counter-expectation is especially obvious in the GO UPC (cf. Bourdin 2003; Schönefeld 2012: 23), but also the other verb-specific UPCs are not free of it. The only exception is the continUE UPC, where the negated participles predominantly report situations considered 'normal': continue unabated, unchanged, unhindered. However, the context - and the use of the CONTINUE UPC in the first place - often make it plain that the continuation of the state in these situations is not a matter of course, as in agonies/disputes/the exodus continue unabated; screams/drugs/pollution continue unchanged, etc.

After elaborating on these more general issues, the next section reports the results as they present themselves at the first level of abstraction, in the verbspecific uses of the UPC. The discussion zooms in on the verb-specific UPCs containing the verbs BE, REMAIN, CONTINUE, SEEM GO, COME, RUN, SEEM, BECOME, GET and GROW. They add to the utterance meanings the specific notions specified in Section 4.1. In order to detect the contribution of the un-participles to these verb-specific constructions in more detail, simple collexeme analyses were carried out for the respective patterns. Additionally, some of the patterns (Go, COME, REMAIN + un-participle) were submitted to a covarying collexeme analysis, including the fillers of the pattern's subject slots into the analysis. ${ }^{20}$ In the sections to come, the results are presented in a summarized form. Complete lists of the top 20 attracted collexemes of selected verb-specific UPCs are listed in Appendix B, the top 10 covarying collexemes of selected verbs - in Appendix C.

\subsection{Characteristics of verb-specific constructions}

The hits of the verb-specific constructions turned out to be related to several clause-level constructions attested in the English language. These are

(i) Copular constructions with a 'current' copula (cf. Quirk et al. 1985: 1,172), instantiated by example (18)

(18) The AM9 kit comes unfinished, so you can paint or stain it to match your decor. (CG5)

20 The subject referents were helpful in the specification of the construction's function, as illustrated below. 
(ii) Copular constructions with a resulting copula, as in example (19)

(19) After 15 minutes we came to the comforting realisation that the phone had come unplugged from its socket. (CBC)

(iii) Intransitive-motion constructions complemented by a depictive, as exemplified by (20)

\section{(20) Brian Everthorpe came uninvited into the room. (ANY)}

Additionally, as a result of the two homonymous un-participle types found in the pattern, the BE and GET UPCs may turn out to be

(iv) (dynamic and stative) passive constructions, as in (21)

(21) ... that all the typewriters had been unplugged from the wall sockets. (HD7)

The examples make it obvious that the (finite) verb is not always diagnostically conclusive for the identification of the constructional function. BE is inconclusive between attributives and passives, and motion verbs, such as go and come, invite a depictive reading, except when the subject is an inanimate referent (incapable of motion), as in (18) and (19). This is where the covarying subjects come in as a diagnostic in that an inanimate subject referent induces a copular reading.

In the following, the four clause-level constructions are labelled as attributive, (subject-) resultative, depictive un-participle and passive constructions respectively, and their meanings/functions can be described as follows:

(1) attributive construction: a state/property is ascribed to the expression's subject referent.

(2) (subject-)resultative construction: a change of state is predicated of the subject referent.

(3) Intransitive motion construction linked with a depictive construction (cf. footnote 18): In cases like these, the UPC (come uninvited in [20]) complements the intransitive motion construction as a secondary predication to the subject, ascribing a property/state to the latter.

(4) passive construction: a transitive event is construed from the perspective of the PATIENT.

Unsurprisingly, construction types and finite verbs are correlated, that is, the former do not distribute evenly across the verb-specific patterns, as shown in Table 2. 
Table 2: Functions of verb-specific un-participle constructions.

\begin{tabular}{llllllllll}
\hline ASC/verb & COME & GO & RUN & BE & GET & SEEM & REMAIN & CONTINUE & BECOME \\
\hline depictive & $\mathrm{X}$ & $\mathrm{X}$ & $\mathrm{X}$ & & & & & $\mathrm{X}$ & \\
attributive & $\mathrm{X}$ & $\mathrm{X}$ & & $\mathrm{X}$ & & $\mathrm{X}$ & $\mathrm{X}$ & & \\
resultative & $\mathrm{X}$ & & & & $\mathrm{X}$ & & & & $\mathrm{X}$ \\
passive & & & & $\mathrm{X}$ & $\mathrm{X}$ & & & & \\
\hline
\end{tabular}

The Come UPC represents depictive, attributive and resultative constructions, the Go UPC - depictive and attributive ones. The RUN UPC has a depictive function. That is, these three verb-specific constructions have the depictive (as in $s b$ ran undetected across the Tower [K95]) in common. Attributive and resultative readings appear to have emerged as grammaticalized extensions of the verbs' motion senses via metaphor (for more details of the historical development of the verb go, cf. Schönefeld 2012, 2013). The BE, SEEM and REMAIN UPCs are found to represent attributive ASCs, which corresponds to the verbs' typical copular function. BE UPCs (and GET UPCs) may also represent passives, namely when the un-participle has a reversative meaning, as in (21) (and (12) (vs (13) and (14) above). The continUE UPC functions as depictive (with a tinge of manner as in the recession continued unabated) and the BECOME UPC represents a resultative ASC (as in Elisabeth's feelings were in danger of becoming unmoored (AEA). From these findings, it can be concluded that the UPCs subsume several constructions at two distinct levels of schematization: at the verb-specific level, we find four clause-level constructions, which in turn allow for further abstraction at the level of verb-group specific constructions (cf. Section 4.4).

The constructional meanings of the individual verb-specific constructions are strongly associated with the verbs used (such as BE vs REMAIN vs GO vs COME, etc.), rendering the aspectual and modal details briefly sketched above (cf. Section 4.1). More particular aspects follow from the un-participles attracted to the constructions, specifically the collexemes identified as distinctive for the constructions analysed. In the following, we have a look at the top 10 collexemes that turned out to be most distinctive for a selection of verb-specific constructions. ${ }^{21}$ They are compiled in Table 3.

The distinctive collexemes reveal clear differences in the meanings of the individual verb-specific constructions. Firstly, we note that the constructions are different with respect to which types of un-participles are most distinctive for them. Judging from the participles' more habitual meanings (cf. Section 4.2), we

21 The computation of the distinctiveness value is briefly illustrated in Appendix D. 


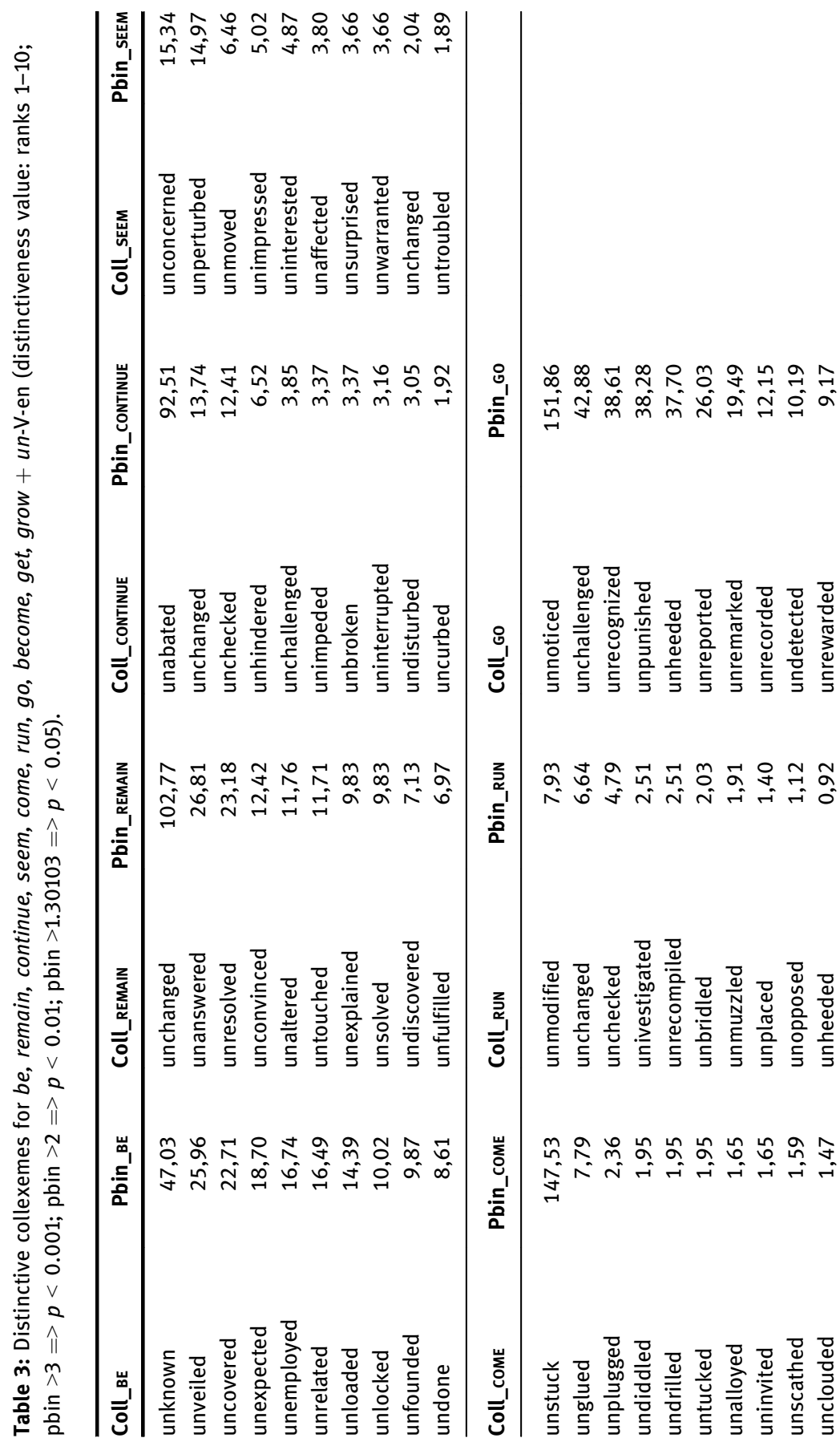




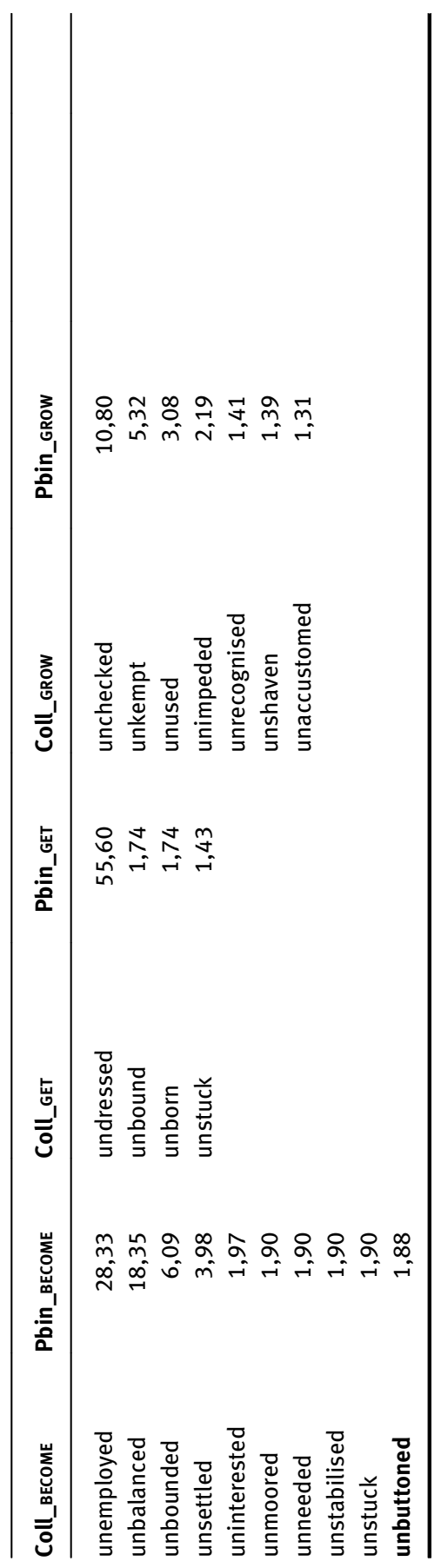


can say that reversative participles are significantly attracted only to the $\mathrm{BE}$, COME, BECOME and GET UPCs. They do, however, not reach the significance level in the remaining UPCS (REMAIN, GO, RUN, SEEM and CONTINUE), though their occurrence is conceivable in principle, e.g., with such verbs as REMAIN or SEEM. ${ }^{22}$ Adjectival un-participles turn out to be significantly distinctive in all UPCs, though they are rare with resulting copulas. Secondly, each verb-specific construction also shows more or less strong preferences for collexemes relating to particular types of events. The isolated event types are borrowed from the repertoire of verb classes Levin (1993) proposed on the basis of their syntactic behaviour. In the following, we summarize the results for the individual verb-specific constructions, considering both aspects.

The collexemes distinctive for the BE UPC comprise a respectable number of habitually reversative participles. They relate to events of disclosure (unveiled, uncovered) and the reversal of various other actions (unloaded, unlocked). In their combination with BE they seem to straightforwardly relate to canonical passives of disclosing and reversative actions. However, quite a few instances present themselves as adjectival participles in an attributive construction, as in (22), so that the form BE plus un-participle correlates with two functions.

(22) As she spoke, Melissa found the door and turned the handle. It was unlocked. (HNJ)

The high-ranking collexemes of a default adjectival nature (negative participles, such as unknown, unexpected) induce state ascriptions and are related to verbs naming psychological states or activities. At the lower ranks, we find verbs of many diverse semantic groups. As has been pointed out (cf. Section 4.2), the attributive constructions predominantly portray situations in which a referent is depicted in a state that follows from an event having failed to materialize, an event that would have been expected in the normal course of events. In a number of cases, this situation is negated, so that we end up with a downtoned positive, as in (23).

22 There were no such hits in the BNC data, but a google search brought up a number of hits, e. g., You hadn't seen it before, and now it seems uncovered, laid bare before your eyes. http:// onakiser.com/2013/11/22/ew-gross/ (accessed 6 November 2014) or Heavy snowfall severely damaged the bridge in 1969 as the weight of more than three feet of snow collapsed the entire roof. Chainsaws were used to saw off the rafters, and the bridge remained uncovered until early spring when county crews reroofed the structure. http://www.oregon.gov/odot/hwy/bridge/docs/ covbrdg/Descriptions/CoyoteCk.pdf (accessed 6 November 2014). 
(23) This method is most often used ... but is not unknown among sociologists. (CMF)

Such 'double negatives' are also found to attract particular collexemes, the most closely associated ones being unknown, unexpected, unrelated, unconnected, unlimited and unaffected. Among them are only few reversative participles, inducing a negated passive reading, as in (24).

(24) Bulk commodity shipments are not unloaded until the bill ... is presented ... (FR7)

Instances of the REMAIN UPC (distinctively) attract alleged adjectival un-participles and represent attributive constructions expressing a diversity of states. The top rank collexemes report situations in which changes did not take place (things remain unchanged, unaltered), things were not communicated (they remain unanswered, unexplained), things were not finished (they remain unresolved, unfulfilled) and others.

Instances of the Go UPC are less diverse than the previous construction. As attributive constructions containing prototypical adjectival un-participles, they often bemoan states following from the absence of events of perception (unnoticed, unrecognized), psychological activity (unchallenged, unheeded) and communication (unreported, unremarked).

Instances of the COME UPC containing prototypical reversative participles often report on undoing acts of combination or attachment (unstuck, unglued), also in the sense of failed action. The verb come, expressing metaphorical motion to a state (as the goal of motion), marks such instances as resultative constructions (implying a change of state) rather than passives. The occurrence in UPCs of BECOME, a resulting copula, is even more straightforward in this respect.

The RUN UPC, giving situations a quasi stative construal (cf. Section 4.1), has fewer distinctive collexemes (most of them habitually adjectival participles), but they have quite diverse meanings. Some instances of the construction report on situations that continue without change, in an established way (unmodified, unchanged), hence lacking the notion of going counter to one's expectations, which is more prominent in REMAIN instances. Other instances, however, are not free of this nuance, as when something runs unchecked or unheeded, for example.

As attributive constructions attracting adjectival un-participles, SEEM UPCs very prominently report on situations when something had not affected people's mental states (but should have done so). This holds true for all of the top 10 collexemes considered, such as unperturbed, unconcerned and unimpressed. 
The continUE UPCs often communicate situations that can extend without restrictions (unabated, unhindered). The consistency of these instances with the notion of unexpectedness (and the critical undertone) of the UPC in general has already been pointed out above (Section 4.2)

The final group to look at are the resultative copulas. All hits of the BECOME UPCs are resultative, expressing a change of state. This is mainly due to the semantics of the (finite) verb, which the OED describes as follows: become II. To come to be. (...) 5. To come to be (something or in some state ... b. with subst. or adj. compl.). The states reported result from undoing an action, that is, the participles relate to reversative verbs (e.g., unbalanced, unbuttoned), or, much less frequently, they result from an 'absent' event (unemployed, uninterested). The other two resultative copulas (GET and GROW) are more frequent in depicitive uses, in which they are intransitive (GROW) or are ambiguous between resultatives and passives (GET).

These facts make it obvious that the distribution of reversative and adjectival participles does not correlate with the four clause-level constructions in a straightforward way. Even after disambiguation of the homonymous participle types, they are found to associate with more than one function. Reversative participles in combination with BE may induce a passive by default, but understood as adjectival participles (cf. ex. (14) and (16) - they participate in attributive constructions as well. Therefore, reversative un-participles cannot serve as an (admittedly convenient) indicator of passive constructions, the less so, because such participles also occur with verbs not involved in passive constructions, namely come (cf. ex. [19]) and BECOME, inducing a resultative reading.

\subsection{Verb-group specific constructions}

It should be natural for the verb-group specific constructions assumed to emerge from verb-specific constructions of the same type to associate with the same clause-level constructions. This holds true for:

(a) UPC with current/stative copula (BE, SEEM, REMAIN, GO, COME) $\rightarrow$ copular construction

(b) UPC with resulting/change-of-state copula (BECOME, GET, GROW, COME) $\rightarrow$ resultative

(c) UPC with motion V (RUN, Go, COME) $\rightarrow$ depictive

and possibly for

(d) UPC with auxiliary verb (BE, GET) $\rightarrow$ passive (resultative)

The status of these more schematic templates (at least a to c) as part of a speaker's grammar is suggested by the number of the related verb-specific 
constructions turning up in the corpus data, the type frequency, that is. If they are psychologically real is, however, an empirical question that would require experimental testing and is not pursued here. Judging from frequency data alone, the results allow for the assumption of verb-specific constructions of at least the more highly frequent verbs, such as the ones listed in Table 2 above, which, in their turn, may give rise to the emergence of the more schematic constructions suggested here in (a) to (c). It is conceivable that also the less frequent verb-specific forms are related to such more schematic construction or to constructions with motion and posture verbs by analogy with the more typical (and hence frequent) verbs of the same group, because, for the analogy to work, the recognition of the more abstract schemata would be required. The data investigated here do not allow for any conclusion with respect to an even more abstract construction of the type "V + un-pp"

\section{Discussion}

The results will now be discussed in accordance with the questions raised in Section 2.

\subsection{What are the characteristics of un-participle constructions?}

Usage data inform us that the formal side of the pattern can be described as "V $\mathrm{V}_{\text {cop/motion/aux }}+$ un-pp" (i.e., a copular/motion/auxiliary verb followed by a predicative complement in the form of a past participle with the prefix un-). Its functional specification depends on a variety of factors. Firstly, the type of verb used is involved: motion Vs tend to trigger depictives, stative copulas - attributives, etc. But, as the data have shown, these correlations are tendencies rather than absolutes. For, motion Vs can also be used as copulas in attributive (Go, COME) and resultative constructions (COME), and, some copulas (BE and GET) also serve the function of passive auxiliaries in passive constructions. A second contributing factor is the type of un-participle. UPCs containing reversative participles are candidates for (dynamic and/or stative) passive constructions (if co-occurring with the verbs BE or GET), and resultative constructions (with BECOME or COME). Adjectival participles (i.e., the ones negated by un-) are predominant in depictive, attributive and resultative constructions. Yet in many cases, the participle type cannot be read off the participles per se, and contextual information needs to be taken into account as a third factor. That means that the 
correlations just given can be confirmed only after the participles have been disambiguated (such that, e.g., unarmed or uncovered are identified as either the participles of their reversative verb bases unarm/uncover or as un-prefixed participles of the prefixless verb bases arm/cover). Despite the probabilistic nature of the correlations given, the data show that the formal template is associated with five different functions: depictive, attributive, resultative, and dynamic and stative passives, all of which clustering around particular (groups of) verbs. We take this to mean that we are concerned with five constructions at the most general level of abstraction. ${ }^{23}$

In light of the functional diversity, it is surprising to see that in the literature the template is termed unpassive. Even more strikingly, the discussions and descriptions given there (cf. Section 1) suggest that the label unpassive is not used for such constructions with reversative participles which actually represent passives (transitive ASCs with PATIENTS as topic), but for those with adjectival participles, which represent attributive argument structure constructions (where voice is not an issue). The allocation to the passive is, therefore, motivated by purely formal considerations. Resultative UPCs, finally, do not attract any comment in the debate about unpassives at all. That is why, a closer investigation into the relationships between (English) UPCs and (English) passive constructions is due.

\subsection{How do UPCs relate to English passive constructions?}

It is apparent that constructions with the verb $\mathrm{BE}$ and participles of reversative verbs qualify as ordinary passives with a dynamic and/or a stative meaning. They construe a transitive event from the perspective of the PATIENT. UPCs with BE and adjectival un-participles look like passives, too, but they communicate states that follow from the fact that (due) events have failed to materialize.

23 As noted by one of the reviewers, it needs to be clarified if the number of constructions cannot be reduced to one or two, with the verbs bringing in the more fine-grained semantic differences. Yet, the data do not speak for such generalisations. Firstly, attributive, resultative and (passive) transitive constructions represent different ASCs whose semantics evoke different basic scenes. Depictive constructions represent secondary predications and, although they allude to attributive constructions, lack a stative copula and combine with dynamic verbs. Moreover, as shown in Table 2, some verbs are involved in more than one construction, so that it is difficult to see how the different meanings can be solely ascribed to them. For dynamic and stative passives, it would not be unfeasible to consider them as one construction with two senses, but as the distinction matters for our analysis, we need to keep them separate. Moreover, the data suggest that the stative passive is closer to the attributive than to the canonical passive. 
This state ascription and the absence of an action scenario distances them from passives (there are no PATIENTS to be topicalized) and identifies them as attributive ASCs. The second straightforward finding is that depictives are unrelated to passives. Again, this is because they do not have PATIENT-subjects. Their subject referents are associated with intransitive (motion) events and hence have characteristics of AGENTS, the prototypical role associated with active constructions. So, what remains to be discussed is if (and in what way) the attributive and the resultative UPCs relate to English passive constructions.

As for the resultative UPCs, they express a change of state. Strictly speaking, this meaning is different from that of the passive, even if the latter is construed statively. Stative passives, such as the table is laid, describe states of PATIENTS after being affected by a process rather than construing states merely as a result of change. It could be argued, though, that the notion of change-of-state resonates in canonical (dynamic) passives as well, where the PATIENT is construed as being acted upon to induce change. However, this change is a stronger or weaker implication of passives: e.g., $X$ was rescued (strong) or $X$ was neglected (weak). In contrast to that, the notion of change-of-state is expressed explicitly by the finite verbs in resultative UPCs: $X$ вгсомE unemployed/unneeded/ untenanted. The message is that the subject referent underwent a change (of state) into a 'new' state. ${ }^{24}$ This holds true for resultative UPCs independently of the participle type (reversatives: $X$ вЕсомE unbalanced/ unbuttoned; $X$ сомE unplugged). That is, the change-of-state meaning of resultative UPCs is mainly an effect of the semantics of the finite verbs. This also explains why the verb slot is constrained to being filled with a resulting copula, such as BECOME, or GROw, excluding the 'current copula' BE. The latter fact distances resultative UPCs from passives on the formal side, for passives prototypically contain the passive marker $\mathrm{BE}$, functioning as an auxiliary rather than a copular verb. ${ }^{25}$

The restriction of resultative UPCs to resulting copulas is corroborated by the data: they co-occur with the verbs BECOME, GET, GROW and (metaphorical) COME. Interestingly, the verb come takes part in a resultative UPC only if the complementing participle relates to a reversative verb. Followed by adjectival un- participles, the instantiations represent depictive or attributive UPCs. This suggests that ComE in this construction is only entrenched in the change-of-state meaning if complemented by a reversative participle. One would have expected otherwise, since resultative come is entrenched for the complementation by an original adjective (as

24 The event inducing the change is usually left unspecified.

25 We abstain from discussing the differences here. Suffice it to say that the passive auxiliary always needs a verbal complementation, whereas a copular verb needs to be complemented by a nominal or an adverbial constituent. 
in $X$ comes true), and negated participles have been found to have characteristics of adjectives rather than verbs (see above, Section 2). The verb Go, entrenched as a grammaticalized resulting copula if complemented by adjectives (as in $X$ goes $m a d$ ), does not occur in resultative UPCs either. The verbs GET and GROW are infrequent in the resultative. GROW coerces its un-participles into a reversative reading, as in (25):

\section{(25) They had grown unaccustomed to using their power (A6V)}

GET can be argued to be a borderline case. It establishes a connection between resultatives and passives, since it is entrenched with both senses. It will be shown in Section 6 that this is a motivated claim indeed.

Turning to attributive UPCs, they also differ from passives. Firstly, the (dynamic) passive meaning of 'a PATIENT being affected by an event' is absent. Attributives construe a stative scenario with no change going on: $X$ remains/is untouched. Obviously, this is also different from stative passives, where a PATIENT's state is expressed as a result of an action directed at it. Secondly, and by implication, the verb in the attributive UPC is - again - of a copular nature rather than a passive auxiliary. We are concerned with the ascription of a state that is a consequence of the respective action failing to materialize. The question is if this does not make them equivalent to negative passives: Compare examples (7), repeated here as (26), and (27)

\section{(26) The material is unabridged and wholly authentic.}

(27) The material has not been abridged and wholly authentic.

At closer inspection, it turns out that the equivalence is deceptive. Besides potential differences in the scope of negation, ${ }^{26}$ the two forms construe two different scenarios. The English negative passive allows for the subject referent to potentially undergo the action at stake, which is why it may co-occur with yet. This observation is compatible with Emonds' (2000: 2) argument that verbal passives do not have a sense of completed activity, which is, however, there in adjectival passives. The notion of completion also matters in attributive UPCs, but not in the sense of completed activity. Rather, it refers to the relevant period considered. An event has not taken place and the chances of its occurrence are over (or blanked out). These semantic differences add to the more general

26 In (27), the scope of negation may, but does not necessarily, extend into the second complement, whereas in (26), it includes the first complement only. 
observations made on the distinct nature of attributives and passives as argument structures and information ordering structures respectively in Section 2. Hence, it is a motivated decision to keep attributive UPCs apart from stative passives, although similarities cannot be denied. For, the stative passive (cf. ex. [28]) shares basic features with the attributive ASC (cf. ex. [29]). Both constructions coincide in that they portray a referent as being in a state:

(28) The house was destroyed.

(29) The house was uninhabited.

For a more detailed discussion of this intricate relationship, we zoom in on attributive UPCs and stative passives.

\subsection{Attributive UPCs and adjectival passives}

Our argument starts out from what is said on these constructions in two representative grammars of Modern English. Huddleston and Pullum (2002: 1,436) argue that stative passives are not passives. They categorize them as complexintransitive constructions, and apply the term 'adjectival passive' to the adjectival predicative complement in such a construction rather than to the complete construction (be + un-participle). For them, only clauses with a dynamic interpretation qualify as passives "in the strict sense". This view attenuates the correlation between passives and UPCs and approximates adjectival passive to attributive ASCs (with adjectival complements). Quirk et al. (1985: 167-171) describe the passive as a gradient comprising central, semi-passives and pseudo-passives. Attributive UPCs can be found as illustrative example sentences in the section about semi-passives, which are said to have verbal and adjectival properties. In particular, they are described as adjectival uses with a stative meaning (cf. Quirk et al. 1985: 168). However, they also fit Quirk et al's description of 'statal passives' as instances of the pseudo-passive. These are characterised - like perfects - as referring to a state resulting from the action specified by the participle's verbal base and their 'statal reading' is equated with a copular one: "the statal passive construction ... is essentially copular, ...” (Quirk et al. 1985: 170). ${ }^{27}$

27 As regards resultative UPCs, they are also understood as copular rather than passive: "Get is much more common as a 'resulting copula' ... and it may be best analysed as such in sentences which look superficially like passives, but which could not be expanded by an agent" (Quirk et al. 1985: 161). At a later place, 'resulting' copular verbs (get, become, grow, etc.) are categorized as pseudo-passives (cf. Quirk et al. 1985: 171). 
If adjectival/stative passives are indeed copular, it needs to be investigated whether, as a consequence, they should be categorized along with attributive UPCs as copular ASCs rather than as passives. To back up such a decision empirically, the UPCs identified in the corpus were analysed for characteristics that are commonly used as diagnostics of adjectival passives, such as absence of agent phrases (by-phrases) and progressives. Their absence/presence should be informative of the nature of the constructions as copular or passive.

\subsubsection{Agent phrases in stative passives and attributive UPCs}

The argument in the previous section suggests that agent phrases should be absent from adjectival passives. However, this assumption is qualified by the recognition of a number of empirical facts in the literature. Quirk et al. (1985: 168) observe that "ed-adjectives may occasionally have agent by-phrases", and therefore exclude the by-phrase as a diagnostic of the passive construction (cf. Quirk et al. 1985: 169). On the other hand, they employ this criterion for defining the category of pseudo-passives. They argue that, as a consequence of the pseudo-passive's copular nature, the addition of an agent phrase is impossible (cf. Quirk et al. 1985: 170). Huddleston and Pullum (2002: 1,439) find that adjectival passives may have by-phrases if their verbal base has a stative rather than a dynamic meaning, as in be worried by sth., granting adjectival passives with un-prefix (i.e., attributive UPCs) even greater freedom in this respect. Also, more theoretical arguments about passives comment on the occurrence of agent phrases. Levin and Rappaport (1988: 647), for example, note that by-phrases "are only sporadically found in adjectival passives" and they concede that it is not clear why adjectival passives and by-phrases are compatible. They qualify the by-phrases in such expressions as often referring to inanimate referents rather than prototypical agents. McIntyre (2013: 30-31) finds that " $b y$-phrases are good if the referent is responsible for continuing the state expressed by the participle ... [and] if the initiator's sortal specifications are crucial for the nature of the state".

These observations tell us that by-phrases should be expected to be quite rare with both adjectival passives and attributive UPCs, but that they should be comparatively more frequent in attributives.

In order to get some usage information on the occurrence of by-phrases in UPCs, the BNC data were checked for by-phrases. Table 4 summarizes the frequencies of $b y$-phrases in some verb-specific UPCs.

As can be seen, the evidence is ambivalent. On average, agent phrases can be found in $8.63 \%$ of the hits, which is not exactly rare. For a more informed 
Table 4: By-phrases and participle types in selected verb-specific UPCs ${ }^{28}$.

\begin{tabular}{lrrrlrrr}
\hline verb & + by & adj coll & total & Verb & + by & adj coll & total \\
\hline be & 644 & 492 & 6,966 & go & 58 & 56 & 599 \\
remain & 85 & 85 & 1,500 & come & 1 & 1 & 109 \\
continue & 0 & 0 & 115 & run & 1 & 1 & 30 \\
seem & 35 & 35 & 142 & become & 3 & 3 & 122 \\
appear & 6 & 6 & 62 & & & & \\
\hline
\end{tabular}

evaluation, we need quantitative data on the occurrence of agent-phrases in passives in general, which is quite difficult to find. Statements that "[t]he majority of passive sentences in English do not include explicit agents to indicate exactly who performed the actions" (Rochester Institute of Technology), ${ }^{30}$ are not specific enough. The same holds for McArthur (1998), who rates the agentless passive as common in both spoken and written English, especially so in formal reports. But Quirk et al. (1985: 164) quantify these facts by stating that roughly 4 out 5 passive sentences have no expressed agent, which means that $20 \%$ do have by-phrases. In comparison to this amount, the percentage calculated for the selected UPCs is noticeably smaller indeed. It must, secondly, be noted that the overall percentage is mainly due to constructions with the current copulas SEEM (24.64\%) and APPEAR (9.67\%), and (grammaticalized) Go (9.34\%), representing attributive UPCs. This fits Huddleston and Pullum's (2002) (quite unspecific) statement that attributive UPCs take agent phrases more freely than adjectival passives. Further evidence for this observation can be found in BE UPCs, where by-phrases occur in attributive uses much more often (roughly 76,4\%) than in passives. The distribution is aligned with the participle type. Reversative participles (152 hits) induce dynamic readings and, hence, represent ordinary passives with by-phrases (ex (30) and [31]):

(30) The painting was unveiled by Lady Ramsay. (K5M)

(31) Teversham was unnerved by the nearness of the following Land Rover (AB9)

Some of these instances turn out to be stative passives (ex (32), and others are ambiguous between passives and attributives (ex [33]).

28 All constructions containing by-phrases were manually inspected for their un-participles to decide on their type (reversative or adjectival) (cf. the argument in Section 4.2).

29 The number of adjectival un-participles is subtracted out of the number of $b y$-phrases.

30 Website information: http://www.rit.edu/ntid/rate/sea/processes/passive/grammatical/ agents, giving Shintani (1979) as a source. 
(32) The 24-year-old, leading scorer ... was unsettled by a 3.5 million offer from Manchester United. (CBD)

(33) So we have gathered here this evening to spend a last evening telling jokes with our friend, who is unfettered by responsibilities (FSN) (ambiguous between not fettered (= adjectival) vs freed from fetters [= reversative])

That is, the occurrence of a by-phrase in BE constructions is more natural in attributive uses (492 hits), though not excluded in adjectival passives. Given all this, we can conclude that by-phrases are noticeably rare in stative passives, but not unusual in (dynamic passives and) attributive constructions. Since the analysis presented here only included participles prefixed by un-, no information could be obtained regarding the number of agent phrases in adjectival passives in general.

A second finding is that by-phrases seem to be attracted by particular collexemes, such as unaffected, unimpressed, unmoved, which relate to verbs expressing psychological states. In instances like these, the by-phrases specify the state at issue rather than representing prototypical agents. A closer look at by-phrases in the BE-UPC (644 instances) in general offers supportive evidence to Levin and Rappaport's (1988) assumption on the character of the by-phrase in stative passives, and we can add to this more exact frequency information.

The majority of the by-phrases has inanimate referents (roughly 76\%), with abstract things (ca. 33\%) and abstract events (almost 14\%) being noticeably frequent. Surprisingly, prototypical agents (animate referents, such as persons, animals and metonymically used names of institutions) are quite frequent, too (almost 17\%). This finding is an effect of constructions with reversative participles (which make passives with agent by-phrases). In constructions with adjectival un-participles, agentive phrases are a lot less frequent (almost 6\%), a fact more in line with what is reported above. Also, McIntyre's idea of a salient initiator's sortal specification is manifest in a noticeable number of instances, as for example in (34) and (35).

(34) ..., but it was untinted by much mutual affection or even comprehension. (EFN)

(35) The judge seemed unimpressed by the argument that a rail strike would cause 'enormous public inconvenience'. (FRT)

That is, the by-phrases identified in the attributive UPCs are different from the ones associated with passives both in a quantitative and a qualitative respect: They are less frequent and prominently refer to entities other than agents. We 
take this to be an indication of the more stative nature of UPCs, allowing for their alignment with a copular ASC rather than passives. Given that by-agents in stative passives are less frequent than in the attributive UPC, such passives are even 'less passive' than the UPCs in this respect, corroborating Huddleston and Pullum's argument given above.

\subsubsection{Progressives in stative passives and attributive UPCs}

The second diagnostic used for the identification of a stative meaning is the distribution of aspect, namely its 'infelicity' with progressives. Therefore, both attributive UPCs and adjectival passives (describing states) are not expected to co-occur with progressives. If a passive co-occurs with the progressive (as in The house was being destroyed - related to example (27) above), the scenario is construed as ongoing, that is, the dynamic meaning of the progressive induces a dynamic reading of the passive.

The data extracted for progressives in the attributive UPC are given in Table 5.

Table 5: Progressives and participle types in selected verb-specific UPCs. ${ }^{31}$

\begin{tabular}{lrrrlrrr}
\hline verb & progr & adj coll $^{\mathbf{3 2}}$ & total & Verb & progr & adj coll & total \\
\hline be & 33 & 0 & 6,966 & go & 5 & 5 & 599 \\
remain & 0 & 0 & 1,500 & come & 1 & 0 & 109 \\
continue & 1 & 0 & 115 & run & 1 & 0 & 30 \\
seem & 0 & 0 & 142 & become & 1 & 0 & 122 \\
appear & 0 & 0 & 62 & & & & \\
\hline
\end{tabular}

The percentage of progressives is very small indeed (0.43\%), and the instantiations in the corpus show that progressives associate with attributive UPCs extremely rarely. All the instances of progressive BE contain reversative un-participles, as in example (36) and, hence, represent dynamic passive constructions:

(36) ..., after firemen were called to a toxic leak of amines while a road tanker was being unloaded. (K4W)

The few hits from other verb-specific constructions are either resultative (with the verbs come and вEсоме) or depictive constructions, as (37) and (38).

31 All constructions containing progressives were manually inspected for their un-participles to decide on their type (reversative or adjectival) (cf. the argument in Section 4.2).

32 The number of adjectival un-participles is subtracted out of the number of progressives. 
(38) ... the stream which had for some time been running unseen beside them. (BMX)

The Go UPC is the only attributive UPC which also has progressives (cf. ex. [39]).

\section{Pollutors are going unpunished ... (J2Y)}

Such uses (representing $0.05 \%$ of the UPCs considered) focus on the persistence of a state. As an effect of the verb Go (triggering the image schema of мотіоN), the state is depicted metaphorically as moving through (the present) time. These particular uses and the absence of progressives in attributive uses are evidential of the stative meaning of this construction, distinguishing it from passive and depictive UPCs which, allowing for dynamic construals, do not block progressives. This finding puts attributive constructions on a par with adjectival passives, which do not unify with progressives either. That is, just like the distribution of by-phrases, the absence of progressives speaks for a closer affinity between stative passives and attributive UPCs rather than between stative and dynamic passives. Such an empirically based categorical alignment is compatible with much of the recent theoretical argument about the passive in Alexiadou and Schaefer (2013), and in Lingua 125 (2013). ${ }^{33}$ Some of the claims that comply with grouping stative passives with attributive ASCs are the following: (a) Adjectival passives are described to exhibit the syntax of sentences with adjectival predicates (as done by Harris 1946; Wasow 1977); (b) Kiparsky (2013: 12) elaborates that "stative passives are clearly passives formally, but they describe ongoing activities or permanent states, not events with a result or consequent state.”); (c) Emonds (2013: 62) claims that adjectival passives are stative, expressing 'completed activity'.

The final issue to be discussed here is the degree of abstractness of the UPCs, already touched upon earlier (cf. Sections 2 and 4).

\subsection{How lexically specific are un-participle constructions?}

The results of the collostruction analyses lend evidence to the fact that UPCs exist at various levels of schematicity. Firstly, the data suggest that speakers of English have available quite a few verb-specific constructions, such as those

33 Here, Hallman and Kallulli (2013: 1-6) - among other things - refer to the distinction between adjectival and verbal passives, which is drawn differently by different authors and models. 
employing the verbs BE, REMAIN, GO, COME, SEEM, etc. Secondly, within these verbspecific constructions, respectable token numbers allow for the assumption of even more specific constructions in which also the slot of the un-participle collexeme is lexically specified. Approaching the question of entrenchment with all due caution (cf. the argument in Section 4.1), token numbers in double figures may provide us at least with candidates for lexically specific constructions, or collocations of the respective verb and un-participle, e.g., those given in Table 6 (for a more informative table see Appendix B).

Table 6: Frequent collexemes in the BE, Go and REMAIN UPC.

\begin{tabular}{lrrrrr}
\hline Verb & collexeme $_{1}$ & collexeme $_{2}$ & collexeme $_{3}$ & collexeme $_{\mathbf{4}}$ & collexeme $_{5}$ \\
\hline BE & unaffected & unchanged & uncovered & unemployed & unknown \\
& $(191 \mathrm{x})$ & $(254 \mathrm{x})$ & $(166)$ & $(397 \mathrm{x})$ & $(557 \mathrm{x})$ \\
\multirow{2}{*}{ GO } & unnoticed & unchallenged & unpunished & unheeded & unrecognized \\
& $(134 \mathrm{x})$ & $(51 \mathrm{x})$ & $(31 \mathrm{x})$ & $(32 \mathrm{x})$ & $(27 \mathrm{x})$ \\
\multirow{2}{*}{ REMAIN } & unchanged & unanswered & unresolved & unconvinced & untouched \\
& $(269 \mathrm{x})$ & $(59)$ & $(52 \mathrm{x})$ & $(39 \mathrm{x})$ & $(46 \mathrm{x})$ \\
& & & & &
\end{tabular}

This list may be complemented with a few examples from the other verb-specific UPCs: come untucked (72 from 98 hits) and become unemployed (50 of 108 hits), instantiating the (subject-) resultative ASC, and continue unabated (52 of 111 hits), instantiating a (subject-) depictive construction. Also, some of the 'double negatives' in the BE UPC qualify as candidates for conventionalised (fully lexicalized) constructions: $B E$ not unknown (112 of 252), BE not unexpected (32), etc. (cf. Section 4.3). Thirdly, results of the covarying collexeme analyses give hints at further lexically specific constructions, in which also the subject phrase is lexically filled. Candidates emerging from the analysis of the REMAIN UPC are for example questions remaining unanswered (51 occurrences) or issues remaining unresolved (16 occurrences, for more examples see Appendix C). The conclusion to be drawn from these data is that some of the verb-specific uses have conventionalised for the expression of particular scenarios, and, by no means, represent 'open choices' for the instantiation of the (more) schematic patterns of ' $\mathrm{X}$ BE/Go/REMAIN/,etc. un-participle'.

At the next higher level, the data support the assumption of verb-group specific un-participle constructions, namely depictive UPCs completing intransitive motion constructions, resultative UPCs containing resulting copular verbs and attributive UPCs containing stative copular verbs (cf. Section 4.4). If only such instantiations are taken as constitutive of the pattern $\mathrm{V}+$ un-participle, the verb slot is constrained to verbs occurring in these ASCs: current and resulting 
copular verbs (or such verbs that can be coerced into the respective ASCs) and intransitive verbs (of motion) (cf. Section 4.1). Further schematization of the verbal slot to 'any verb' is not likely. ${ }^{34}$ This makes it obvious that, talking about the UPC as defined here, we are concerned with a so-called 'mid-level construction', where only some of the slots have a purely schematic form. In the UPC, the verb slot is constrained to be filled by verbs of particular groups and the participles contain the lexically specific prefix $u n-$.

In the last section, we will conclude what the analysis reported here reveals about the relation between the UPCs summarized so far and passive constructions.

\section{Conclusion}

The study at hand has shown that the formal pattern ' $\mathrm{V}_{\text {cop/motion/aux }}+$ un-pp' is linked with several functions. Such instances that ascribe states to their subject referents, construing them as CARRIERS of properties (or EXPERIENCERS of change) represent depictive, attributive or resultative constructions, whereas instances portraying a subject referent as affected by an event, as a PATIENT, are passive constructions. Given that constructions emerge from the experience of exemplars in linguistic interaction (cf. Ellis and Larsen-Freeman 2009: 92) and that the resulting categories "are structured by similarity and frequency, and often exhibit prototype effects" (Bybee 2013: 52), it is not implausible to assume that all of these constructions are associated in an exemplar cloud or a network. They are grouped together because some of them have similar functions and all of them share lexical material. The prefix un- is present in all exemplars, and some of the verbs are shared between them (BE and motion verbs in particular).

Depictive UPCs are semantically linked with the more schematic attributive construction in that they inherit the function of expressing states. But they lack a copula and their function is more specific. They relate to predications that contain AGENT subjects, to which they concomitantly ascribe a state. That is why the subjects are also CARRIERs of states. ${ }^{35}$ This is what distances them from (dynamic and stative) passives, which have PATIENT subjects. However, they are

34 This seems at odds with the high number of verb types for the pattern ' $\mathrm{V}$ un-participle (=adjective)' (268). However, it must be noted that many of them turned out to be non-finite, namely past participles of ordinary passives with the un-participle related to the object (i.e., object-depictives) (cf ex (9) above). All these were not part of our investigation, which is confined to UPCs that bring about state ascriptions, that is attributive and resultative constructions, and subject-related depictives.

35 This is a problem in generative theorizing in that such utterances violate the theta criterion, which, according to Chomsky (1981: 36), claims that "Each argument bears one and only one 
formally linked with them via their un-participle components. The latter add their own semantic specifics (as spelled out in Section 4.2) to the expressions.

Attributive UPCs are linked with the more schematic attributive construction (current copula + adjective), inheriting central aspects from it. They express states, properties or attributes of the subject referents, they contain the same copular verbs (BE, REMAIN, SEEM, APPEAR, etc.) and do not attract progressives. Their subject referents are CARRIERS of the states. Attributive UPCs also share features with stative passives. They both portray their subject referents as CARRIERS of states. However, this follows from 'inverse' situations. The state ascribed in attributive UPCs is due to the nonoccurrence of an (expected) event, whereas the one ascribed in a passive follows from an event that did affect the subject referent, so that a 'change-of-state' can be inferred. Moreover, just like passives, attributive UPCs may contain AGENT byphrases. Their frequency of occurrence as well as their semantic specifics (cf. Section 5.3.1) seem to be similar to that of by-phrases in stative passives. More peripherally, their passive feel may be enhanced by the existence of " $\mathrm{BE}+$ un-pp" uses that can be ambivalent between an attributive, a dynamic or stative passive reading, ${ }^{36}$ as e.g., BE unarmed/uncovered and others (cf. Section 4.2).

Against this backdrop, it can be argued that the attributive UPC is a subconstruction of the more schematic attributive ACS, with the predicative complement specified as an un-prefixed participle. At the same time, functional overlap links it to stative passives in the exemplar cloud. Such a link was found to be effective in language acquisition when children generalize lexical forms across constructions. Abbot-Smith and Behrens (2006: 995) report on a German-learning child, whose acquisition of the sein-passive was supported by prior acquisition of the copular use of sein.

Resultative UPCs, expressing a change-of-state, represent a sub-construction of the (subject-) resultative ASC. The verbs they contain (BECOME, COME, GET, and GROW) make the meaning of change-of-state explicit. This notion was found to resonate in passives as well (cf. Section 5.2), so that it may be understood as a semantic link between resultatives and passives. A developmental study of the passive lends evidence to this. Israel et al. (2000: 104-105) report that in childrens' acquisition of the passive, stative, adjectival participles regularly precede eventive, verbal

$\theta$-role, and each $\theta$-role is assigned to one and only one argument.” The problem is avoided by describing and analysing depictives as small clauses realizing secondary predications, as done by Chomsky himself (1981: 110-111) and others (cf. Rapoport 1990, 1999; Rothstein 2003, 2006; Schultze-Berndt and Himmelmann 2007: 74-77, for example).

36 Given that the English passive construction has developed from a copula construction “instantiating a type of VI predication and involving adjectival predicates" (Petré 2014; cf. also Toyota 2008) and have co-existed from then on, this does not come as a surprise 
participles, and that this development is assisted by the form GET + participle (e.g., the dynamic passive reading of sth is broken/fixed is assisted by sth gets fixed/ broken). That is, due to its explicit meaning of change-of-state, the GET + participle construction functions as a bridging context for dynamic passives. Secondly, resultative constructions express a change-of-state disregarding its cause or trigger (cf. ex. [40]). Also in this respect, they resemble passives, which are known to allow for the 'demotion'of the AGENT (the causer or trigger of transitive events).

(40) ... a number of warren systems inevitably became untenanted. (BNY)

This functional analogy further enhances the affiliation of passives with resultative copular constructions (and resultative UPCs).

In sum, the types of UPCs identified in the data fit the idea of a network of constructions related to one another via schematization/instantiation links (as discussed in Diessel 2015), and by shared semantic features accounting for relations of family resemblance (as shown in Bybee 2013: 57-58). Further evidence for the network to exist must come from psycholinguistic investigations. For example, priming experiments could be designed to find out if the constructions postulated to be related prime one another. If priming effects can be found, this will speak for their association in an activation network of grammatical constructions (cf. Diessel 2015).

Figure 1 is meant to illustrate the network of UPCs, all of which are concerned with the expression of states. Depictive UPCs portray an acting subject as

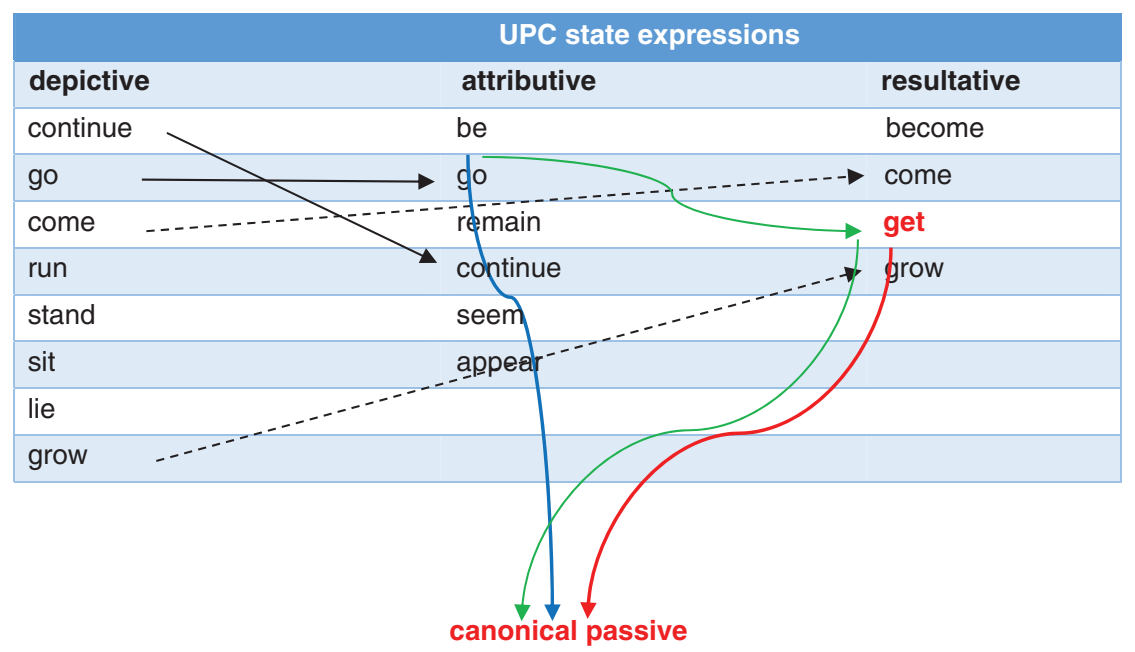

Figure 1: The network of UPCs. 
being in a state, attributive UPCs ascribe states to their subjects, resultative UPCs are concerned with their change-of-state, and passives report on subjects affected by an action which may have induced some change(-of-state). The sketch employs information on how the network emerged, supported by such item-based extensions as described in grammaticalization and developmental studies. Depictive Go and come have grammaticalized (by metaphorical extension) to attributive and resultative uses respectively (black lines). Attributive uses have extended to passive uses (blue line) mediated by resultatives (red and green lines). These connections can still be noticed in the formal and functional overlap of the constructions. The overall picture suggests that attributive constructions are prototypes of state expressions, with change-of-state constructions establishing an association to canonical passives, which in their turn are typically associated with action scenes, in which an AGENT acts upon a PATIENT. In addition to the functional associations specified above, the shared lexical material makes it plausible to assume massive interconnections between these constructions.

On a more general level, the argument developed here for the network of UPCs and the passive can be extended to hypothesizing about the status of adjectival passives in general. The question is whether adjectival passives should be grouped with attributive ASCs rather than with passive constructions. The data investigated here are consonant with this hypothesis, which is why we would want to answer this issue in the affirmative.

Acknowledgements: This article originates in a talk given at ICLC 12. I wish to thank my anonymous reviewers and one of the journal's associate editors for their very helpful pointers, suggestions and comments on an earlier draft. Also, I would like to thank Stefan Th. Gries for the generous provision of the software Coll.Analysis 3.2a in R, which I used for carrying out all collostruction analyses referred to. All remaining errors are my own.

\section{References}

Aarts, Bas. 1995. Secondary predicates in English. In Bas Aarts \& Charles Meyer (eds.), The verb in contemporary English - theory and description, 75-101. Cambridge: Cambridge University Press.

Abbot-Smith, Kirsten F. \& Heike Behrens. 2006. How known constructions influence the acquisition of other constructions: The German passive and future constructions. Cognitive Science 30(6). 995-1026.

Alexiadou, Artemis \& Florian Schaefer (eds.). 2013. Non-canonical passives, 21-42. Amsterdam: John Benjamins. 
Barlow, Michael \& Suzanne Kemmer (eds.). 2000. Usage-based models of language. Stanford, CA: Center for the Study of Language and Information Publications.

Bourdin, Philippe. 2003. On two distinct uses of go as a conjoined marker of evaluative modality. In Roberta Facchinetti, Manfred Krug \& Frank Palmer (eds.), Modality in contemporary English, 103-127. Berlin: Mouton de Gruyter.

Bresnan, Joan. 1978. A realistic transformational grammar. In Morris Halle, Joan Bresnan \& George A. Miller (eds.), Linguistic theory and psychological reality, 1-59. Cambridge, MA: MIT Press.

Bybee, Joan. 2006. From usage to grammar: The mind's response to repetition. Language 82(4). 711-733.

Bybee, Joan. 2013. Usage-based theory and exemplar representations of constructions. In Thomas Hoffmann \& Graeme Trousdale (eds.), Handbook of construction grammar, 49-69. Oxford: Oxford University Press.

Bybee, Joan \& Paul Hopper (eds.). 2001. Frequency and the emergence of linguistic structure. Amsterdam: John Benjamins.

Chomsky, Noam. 1981. Lectures on government and binding. Dordrecht: Foris Publications.

Comrie, Bernard. 1981. Language universals and linguistic typology: Syntax and morphology. Oxford: Blackwell \& Chicago: University of Chicago Press.

Diessel, Holger. 2007. Frequency effects in language acquisition, language use, and diachronic change. New Ideas in Psychology 25. 108-127.

Diessel, Holger. 2015. Usage-based construction grammar. In Ewa Dabrowska \& Dagmar Divjak (eds.), Handbook of cognitive linguistics, 296-322. Berlin: De Gruyter.

Ellis, Nick \& Diane Larsen-Freeman. 2009. Constructing a second language: Analyses and computational simulations of the emergence of linguistic constructions from usage. Language Learning 59(1). 90-125.

Embick, David. 2004. On the structure of resultative participles in English. Linguistic Inquiry 35(3). 355-392.

Emonds, Joseph. 2000. Lexicon and grammar: The English syntacticon. Berlin: Mouton de Gruyter. sils.shoin.ac.jp/ jeemonds/3WEB_OK_Passives_and_Perfects_(POST).doc (a condensed version of chapter 5).

Emonds, Joseph. 2006. Adjectival passives: The construction in the iron mask. In Martin Everaert, Henk van Riemsdijk, Rob Goedemans \& Bart Hollebrandse (eds.), The Blackwell companion to syntax, 16-60. Malden, MA: Blackwell.

Emonds, Joseph. 2013. Indirect passives and the selection of English participles. Lingua 125. 58-75.

Goldberg, Adele. 1995. A construction grammar approach to argument structure. Chicago: University of Chicago Press.

Goldberg, Adele. 1998. Patterns of experience in patterns of language. In Michael Tomasello (ed.), The new psychology of language, 203-219. Mahwah, NJ: Erlbaum.

Goldberg, Adele. 2003. Constructions: A new theoretical approach to language. Trends in Cognitive Science 7(5). 219-224.

Goldberg, Adele. 2006. Constructions at work. Oxford: Oxford University Press.

Gries, Stefan Th. 2007. Coll.analysis 3.2a. A program for R for Windows 2.x.

Gries, Stefan Th \& Anatol Stefanowitsch. 2004. Covarying collexemes in the Into-causative. In Michel Achard \& Suzanne Kemmer (eds.), Language, culture, and mind, 225-246. Stanford, CA: Center for the Study of Language and Information Publications. 
Halliday, Michael A.K. 1967. Notes on transitivity and theme in English, Part 1. Journal of Linguistics 3. 37-81.

Hallman, Peter \& Dalina Kallulli. 2013. Introduction to special issue. Lingua 125. 1-6.

Hampe, Beate \& Doris Schönefeld. 2006. Syntactic leaps or lexical variation? More on "Creative Syntax". In Stefan Gries \& Anatol Stefanowitsch (eds.), Corpora in cognitive linguistics. Corpus-based approaches to syntax and lexis, 127-157. Berlin \& New York: Mouton de Gruyter.

Harris, Zellig. 1946. From morpheme to utterance. Language 22(3). 161-183.

Himmelmann, Nikolaus \& Eva Schulze-Berndt. 2005. Issues in the syntax and semantics of participant-oriented adjuncts: An introduction. In Nikolaus Himmelmann \& Eva SchulzeBerndt (eds.), Secondary predication and adverbial modification, 1-67. Oxford: Oxford University Press.

Hopper, Paul J. 1987. Emergent grammar. Berkeley Linguistics Society 13. 139-157.

Huddleston, Rodney D. \& Geoffrey K. Pullum. 2002. The Cambridge grammar of the English language. Cambridge: Cambridge University Press.

Hust, Joel R. 1977. The syntax of the unpassive construction in English. Linguistic Analysis 3(1). 31-63.

Israel, Michael, Christopher Johnson \& Patricia J. Brooks. 2000. From states to events: The acquisition of English passive participles. Cognitive Linguistics 11(1/2). 103-129.

Kiparsky, Paul. 2013. Towards a null theory of the passive. Lingua 125. 7-33.

Langacker, Ronald W. 1987. Foundations of cognitive grammar. Vol. 1. Theoretical Prerequisites. Stanford, CA: Stanford University Press.

Langacker, Ronald W. 2000. A dynamic usage-based model. In Michael Barlow \& Suzanne Kemmer (eds.), Usage-based models of language, 1-63. Stanford, CA: Center for the Study of Language and Information Publications.

Langacker, Ronald W. 2008. Cognitive grammar. Oxford: Oxford University Press.

Lee, David Y. W. 2001. Genres, registers, text types, domains and styles: Clarifying the concepts and navigating a path through the BNC jungle. Language Learning and Technology 5(3).

37-72. http://llt.msu.edu/vol5num3/lee/default.html (accessed 5 October 2013).

Levin, Beth. 1993. English verb classes and alternations. Chicago: University of Chicago Press.

Levin, Beth \& Malka Rappaport. 1988. The formation of adjectival passives. Linguistic Inquiry 17(4). 623-661.

Maienborn, Claudia. 2007. Das Zustandspassiv. Zeitschrift für Germanistische Linguistik 35(1-2). 83-114.

McArthur, Tom. 1998. Agentless passive. Concise Oxford Companion to the English Language. Encyclopedia.com. http://www.encyclopedia.com (accessed 15 June 2013).

McIntyre, Andrew. 2013. Adjectival passives and adjectival participles in English. In Artemis Alexiadou \& Florian Schaefer (eds.), Non-canonical passives, 21-42. Amsterdam: John Benjamins.

Meltzer-Asscher, Aya. 2010. Present participles: Categorial classification and derivation. Lingua 120, 2211-2239.

Petré, Peter. 2014. Constructions and environments. Copular, passive and related constructions in Old and Middle English. Oxford: Oxford University Press.

Quirk, Randolph, Sidney Greenbaum, Geoffrey Leech \& Jan Svartvik. 1985. A comprehensive grammar of the English language. Edinburgh: Longman.

Rapoport, T. R. 1990. Secondary predication and the lexical representation of verbs. Machine Translation 5. 31-55. 
Rapoport, T. R. 1999. Structure, aspect and the predicate. Language 75(4). 653-677.

Robins, Robert H. 1992. The development of the word class system of the European grammatical tradition. In Burkhard Schaeder \& Clemens Knobloch (eds.), Wortarten, 315-332. Tübingen: Max Niemeyer.

Rothstein, Susan. 2003. Secondary predication and aspectual structure. In Ewald Lang, Claudia Maienborn \& Catherine Fabricius-Hansen (eds.), Modifying adjuncts, 553-590. Berlin: Mouton de Gruyter.

Rothstein, Susan. 2006. Secondary predication. In Martin Everaert, Henk van Riemsdijk, Rob Goedemans \& Bart Hollebrandse (eds.), The Blackwell companion to syntax, 209-233. Malden, MA: Blackwell.

Saeed, John I. 2008 [1997]. Semantics. Malden, MA: Blackwell.

Schönefeld, Doris. 2012. Things going unnoticed - A usage-based analysis of go-constructions. In Stefan Th. Gries \& Dagmar Divjak (eds.), Frequency effects in language representations, 11-49. Berlin: Mouton de Gruyter.

Schönefeld, Doris. 2013. Go mad - come true - run dry: Metaphorical motion, semantic preference(s) and deixis. In Anatol Stefanowitsch (ed.), Yearbook of the German Cognitive Linguistics Association 1, 215-135. Berlin: Mouton de Gruyter.

Schultze-Berndt, Eva \& Nikolaus Himmelmann. 2004. Depictive secondary predicates in crosslinguistic perspective. Linguistic Typology 8. 59-131.

Shintani, M. 1979. The frequency and usage of the English passive. Los Angeles, unpublished University of California dissertation. (quoted from http://www.rit.edu/ntid/rate/sea/processes/passive/grammatical/agents, accessed 25 September 2013).

Sinclair, John McH. 1991. Corpus, concordances, collocations. Oxford: Oxford University Press.

Stefanowitsch, Anatol \& Stefan Th. Gries. 2003. Collostructions: Investigating the interaction between words and constructions. International Journal of Corpus Linguistics 8(2). 209243.

Stefanowitsch, Anatol \& Stefan Th. Gries. 2005. Covarying collexemes. Corpus Linguistics and Linguistic Theory 1(1). 1-43.

Stefanowitsch, Anatol \& Stefan Th. Gries. 2009. Corpora and grammar. In Anke Lüdeling \& Merja Kytö (eds.), Corpus linguistics. An international handbook, 933-952. Berlin: Mouton de Gruyter.

Toyota, Junichi. 2008. Diachronic change in the English passive. Basingstoke: Macmillan.

Wasow, Thomas. 1977. Transformations and the lexicon. In Peter W. Culicover, Thomas Wasow \& Adrian Akmajian (eds.), Formal Syntax, 327-360. New York: Academic Press.

Zimmer, Ben. 2009. The un-believable un-verb, In Word Routes. Exploring the pathways of our lexicon. http://www.visualthesaurus.com/cm/wordroutes/the-un-believable-un-verb/ (accessed 20 August 2013). 


\section{Appendix A: Verbs in the UPC (raw frequencies, top 30 ranks)}

\begin{tabular}{llrrlrrlr}
\hline rank & verb & frequency & rank & Verb & frequency & rank & verb & frequency \\
\hline 1 & be & 6,966 & 11 & lie & 68 & 21 & work & 24 \\
2 & remain & 1,500 & 12 & escape & 68 & 22 & arrive & 23 \\
3 & go & 599 & 13 & appear & 62 & 23 & emerge & 21 \\
4 & seem & 142 & 14 & stand & 54 & 24 & grow & 21 \\
5 & become & 122 & 15 & stay & 35 & 25 & walk & 19 \\
6 & continue & 115 & 16 & get & 34 & 26 & sound & 17 \\
7 & come & 109 & 17 & survive & 31 & 27 & flow & 15 \\
8 & pass & 87 & 18 & run & 30 & 28 & sit & 14 \\
9 & feel & 85 & 19 & prove & 30 & 29 & rise & 10 \\
10 & look & 83 & 20 & die & 27 & 30 & fall & 9 \\
\hline
\end{tabular}

\section{Appendix B: Simple collexeme analysis of BE,} Remain, GO, COME, RUN, SEem, CONTINUE + un-participle

\begin{tabular}{|c|c|c|c|c|c|c|c|c|}
\hline rank & $\mathrm{BE}$ & $\begin{array}{l}\text { Coll. } \\
\text { str }^{\mathrm{a}}\end{array}$ & REMAIN & $\begin{array}{r}\text { Coll. } \\
\text { str. }\end{array}$ & GO & $\begin{array}{r}\text { Coll. } \\
\text { str. }\end{array}$ & COME & $\begin{array}{r}\text { Coll. } \\
\text { str. }\end{array}$ \\
\hline 1 & unaffected & $\operatorname{Inf}$ & unchanged & $\operatorname{lnf}$ & unnoticed & Inf & unstuck & $\operatorname{lnf}$ \\
\hline 2 & unchanged & $\operatorname{Inf}$ & unanswered & 134,52 & unchallenged & 149,04 & unglued & 16,10 \\
\hline 3 & uncovered & $\operatorname{Inf}$ & unresolved & 106,41 & unpunished & 112,50 & unprepared & 6,75 \\
\hline 4 & unemployed & $\operatorname{Inf}$ & untouched & 102,54 & unheeded & 110,69 & unplugged & 6,052 \\
\hline 5 & unknown & $\operatorname{Inf}$ & unconvinced & 95,39 & unrecognized & 79,67 & unscathed & 4,42 \\
\hline 6 & unshaved & $\operatorname{Inf}$ & unaltered & 91,39 & unreported & 68,96 & undiddled & 4,31 \\
\hline 7 & unveiled & $\operatorname{lnf}$ & unknown & 78,87 & unremarked & 53,12 & undrilled & 3,84 \\
\hline 8 & unloaded & 215,97 & unaffected & 61,12 & unrecorded & 43,44 & untucked & 3,84 \\
\hline 9 & unrelated & 192,35 & unmoved & 40,08 & unanswered & 43,02 & unfastened & 3,47 \\
\hline 10 & unmarried & 192,04 & undetected & 38,05 & undetected & 42,79 & unalloyed & 2,93 \\
\hline 11 & unprepared & 185,79 & unsolved & 35,50 & unchecked & 25,70 & unclouded & 2,93 \\
\hline 12 & undone & 171,91 & undisturbed & 31,85 & unrewarded & 25,69 & unheralded & 2,90 \\
\hline 13 & unjustified & 147,52 & unproven & 31,00 & unheard & 21,72 & unbound & 2,84 \\
\hline 14 & unheard & 143,29 & unexplained & 29,94 & unmentioned & 17,36 & undiluted & 2,51 \\
\hline 15 & unexpected & 140,09 & undecided & 29,60 & unstated & 10,73 & unhindered & 2,42 \\
\hline
\end{tabular}


(continued)

\begin{tabular}{|c|c|c|c|c|c|c|c|c|}
\hline rank & BE & $\begin{array}{l}\text { Coll. } \\
\text { str }^{\text {a }}\end{array}$ & REMAIN & $\begin{array}{l}\text { Coll. } \\
\text { str. }\end{array}$ & GO & $\begin{array}{l}\text { Coll. } \\
\text { str. }\end{array}$ & СоME & $\begin{array}{l}\text { Coll. } \\
\text { str. }\end{array}$ \\
\hline 16 & unlocked & 137,30 & unfulfilled & 29,47 & unobserved & 10,26 & uninvited & 2,39 \\
\hline 17 & unimpressed & 135,25 & unchallenged & 29,27 & undiagnosed & 10,19 & unannounced & 2,35 \\
\hline 18 & undecided & 131,17 & undiscovered & 27,78 & unquestioned & 10,12 & unopened & 2,30 \\
\hline 19 & unfounded & 119,39 & unsold & 27,03 & unseen & 9,99 & unchecked & 2,14 \\
\hline 20 & unearthed & 116,40 & undeveloped & 24,04 & unsatisfied & 7,86 & undone & 1,89 \\
\hline rank & RUN & & SEEM & & CONTINUE & & & \\
\hline 1 & unchanged & 35,07 & unconcerned & 48,93 & unabated & 210,63 & & \\
\hline 2 & unmodified & 13,73 & unperturbed & 37,98 & unchecked & 34,50 & & \\
\hline 3 & unchecked & 12,28 & unaffected & 32,11 & unchanged & 19,33 & & \\
\hline 4 & unrecompiled & 4,57 & unmoved & 26,45 & undisturbed & 11,49 & & \\
\hline 5 & unmuzzled & 4,09 & unimpressed & 24,06 & unhindered & 11,01 & & \\
\hline 6 & unplaced & 3,57 & uninterested & 15,30 & unbroken & 8,76 & & \\
\hline 7 & uninvestigated & 3,14 & untouched & 12,07 & uninterrupted & 6,89 & & \\
\hline 8 & unheeded & 3,06 & undecided & 11,57 & unimpeded & 5,40 & & \\
\hline 9 & unbridled & 3,00 & unconvinced & 9,68 & undiminished & 5,27 & & \\
\hline 10 & undetected & 2,76 & unwarranted & 6,74 & unilluminated & 4,29 & & \\
\hline 11 & unopposed & 2,73 & unjustified & 6,46 & unchallenged & 4,23 & & \\
\hline 12 & unchallenged & 2,54 & unprepared & 6,40 & uncurbed & 3,99 & & \\
\hline 13 & & & unconnected & 6,38 & unresolved & 3,84 & & \\
\hline 14 & & & unsurprised & 5,82 & unamended & 3,11 & & \\
\hline 15 & & & unimpaired & 5,37 & unrelieved & 2,57 & & \\
\hline 16 & & & undaunted & 4,66 & untainted & 2,54 & & \\
\hline 17 & & & unattracted & 4,20 & unfilled & 2,50 & & \\
\hline 18 & & & unhaunted & 4,20 & unabashed & 2,50 & & \\
\hline 19 & & & unoffended & 4,20 & unobserved & 2,34 & & \\
\hline 20 & & & unknown & 3,76 & undeterred & 2,33 & & \\
\hline
\end{tabular}

A = collostruction strength (Coll.strength $>3=>p<0.001$; coll.strength $>2=>p<0.01$; coll.strength $>1.30103=>p<0.05$ ) 


\section{Appendix C: Covarying collexemes of GO, REMAIN and COME + un-participle (top 20 pairs)}

\begin{tabular}{|c|c|c|c|c|c|}
\hline words1 Go & words2 & coll.strength & words1 & words2 & coll.strength \\
\hline untreated & tumour & 7.42 & unchallenged & statement & 3.10 \\
\hline unheeded & warning & 6.27 & undetected & error & 2.98 \\
\hline unanswered & plea & 4.80 & unaccompanied & staff & 2.73 \\
\hline unmet & need & 4.37 & unactioned & complaint & 2.73 \\
\hline unheeded & call & 4.25 & unbeaten & we & 2.73 \\
\hline unreported & case & 4.17 & unchastened & impudence & 2.73 \\
\hline unasked & question & 4.16 & unclaimed & pence & 2.73 \\
\hline unanswered & letter & 3.84 & uncompensated & loser & 2.73 \\
\hline unchecked & rising & 3.61 & unconfirmed & rumour & 2.73 \\
\hline unheard & voice & 3.42 & unconsidered & objection & 2.73 \\
\hline words1 REMAIN & words2 & coll.strength & words1 & words2 & coll.strength \\
\hline unanswered & Questions & 70.91 & unconvinced & I & 5.64 \\
\hline unresolved & Issues & 18.56 & unsolved & murder & 5.64 \\
\hline unmarried & women & 17.57 & unexpired & years & 5.44 \\
\hline unchanged & rates & 8.97 & unresolved & problems & 5.39 \\
\hline unsolved & problems & 8.89 & unsold & shares & 5.39 \\
\hline unstirred & water & 8.55 & unknown & whereabouts & 5.25 \\
\hline unbeaten & team & 7.56 & undone & chores & 5.14 \\
\hline untapped & Potential & 6.20 & unaccounted & bodies & 4.92 \\
\hline unfilled & posts & 6.01 & unaccounted & prisoners & 4.92 \\
\hline unpaired & males & 5.92 & unbroken & silence & 4.92 \\
\hline words1 COME & words2 & coll.strength & words1 & words2 & coll.strength \\
\hline unglued & She & 2.90 & unheralded & thoughts & 1.99 \\
\hline unprepared & They & 2.35 & unhindered & light & 1.99 \\
\hline unalloyed & Benefits & 1.99 & unnoticed & vapour & 1.99 \\
\hline unannounced & member & 1.99 & untucked & towel & 1.99 \\
\hline unbound & Hair & 1.99 & unmarked & anything & 1.69 \\
\hline unchecked & phone_calls & 1.99 & unplugged & phone & 1.69 \\
\hline undiluted & Traits & 1.99 & uninvited & proper & 1.51 \\
\hline undone & Bandage & 1.99 & unclouded & it & 1.39 \\
\hline unfastened & Buttons & 1.99 & undiddled & it & 1.39 \\
\hline unfinished & Kit & 1.99 & unglued & design & 1.39 \\
\hline
\end{tabular}




\section{Appendix D: Information on the multiple distinctive collexeme analysis carried out for this study}

The computation in a multiple distinctive collexeme analysis is illustrated here for the collexeme unnoticed. The analysis starts out from the observed frequencies of the un-V-en collexemes in each verb-specific construction, which is (for unnoticed) as given below, making up a total of 163 occurrences. On the basis of the total frequencies of the verb-specific constructions $(6,966,122,109,115,35$, $599,21,1500,30,142)$, the programme calculates the expected frequency, that is, the frequency that would be expected if the 163 occurrences of unnoticed were distributed in proportions matching those of the different verb-specific constructions. Then, a binomial test is performed to establish the probability of a particular observed frequency given the expected frequency (e.g., the probability to find 5 occurrences of unnoticed with REMAIN when you would have expected it 25.4 times). This probability is then log-transformed (=log10 pbinomial value) and is given as a positive number when the collexeme occurs more frequently than expected in the respective verb-specific construction, and as a negative number when it occurs less frequently than expected (Pbin).

\begin{tabular}{|c|c|c|c|c|c|c|c|c|c|c|}
\hline verb & be & become & come & continue & get & go & grow & remain & run & seem \\
\hline observed frequency & 10 & 1 & 1 & 1 & 0 & 145 & 0 & 5 & 0 & 0 \\
\hline expected frequency & 177.8 & 2.1 & 1.8 & 1.9 & 0.6 & 10.1 & 0.4 & 25.4 & 0.5 & 2.4 \\
\hline Pbin & -71.2 & -0.4 & -0.3 & -0.4 & -0.2 & 151.8 & -0.1 & -6.6 & -0.2 & -1.0 \\
\hline
\end{tabular}

